\title{
Metabolic and bioprocess engineering for production of selenized yeast with increased content of seleno-methylselenocysteine
}

\author{
Valeria Mapelli $^{\text {a,*}}$, Peter R. Hillestrøm ${ }^{\text {b,1 }}$, Emese Kápolna ${ }^{\text {b,1 }}$, Erik H. Larsen ${ }^{\text {b }}$, Lisbeth Olsson ${ }^{\text {a }}$ \\ a Department of Chemical and Biological Engineering, Chalmers University of Technology, Kemigården 4, 41296, Göteborg, Sweden \\ ${ }^{\mathrm{b}}$ National Food Institute, Technical University of Denmark, Mørkhøj Bygade 19, 2860, Søborg, Denmark
}

\section{A R T I C L E I N F O}

\section{Article history:}

Received 26 August 2010

Received in revised form

7 January 2011

Accepted 1 March 2011

Available online 10 March 2011

\section{Keywords:}

Yeast

Seleno-methylselenocysteine

Selenium and sulfur metabolism

Mass spectrometry

Fed-batch

Metabolic engineering

\begin{abstract}
A B S T R A C T
Specific Se-metabolites have been recognized to be the main elements responsible for beneficial effects of Se-enriched diet, and Se-methylselenocysteine (SeMCys) is thought to be among the most effective ones. Here we show that an engineered Saccharomyces cerevisiae strain, expressing a codon optimized heterologous selenocysteine methyltransferase and endowed with high intracellular levels of $S$-adenosyl-methionine, was able to accumulate SeMCys at levels higher than commercial selenized yeasts. A fine tuned carbon- and sulfate-limited fed-batch bioprocess was crucial to achieve good yields of biomass and SeMCys. Through the coupling of metabolic and bioprocess engineering we achieved a $\sim 24$-fold increase in SeMCys, compared to certified reference material of selenized yeast. In addition, we investigated the interplay between sulfur and selenium metabolism and the possibility that redox imbalance occurred along with intracellular accumulation of Se. Collectively, our data show how the combination of metabolic and bioprocess engineering can be used for the production of selenized yeast enriched with beneficial Se-metabolites.
\end{abstract}

(c) 2011 Elsevier Inc. All rights reserved.

\section{Introduction}

Selenium (Se) is an essential micronutrient for many organisms, including humans, and the production of selenized yeast, aiming to prevent Se shortage in nutrition, has long been considered. Interest in Se-enriched yeast has been further triggered by the clinical trial reported by Clark et al. (1996), which showed that supplementation of a randomized group of people with supra-nutritional doses of Se as Se-enriched yeast prevented the incidence of some cancer forms by nearly 50\%. Diverse molecular mechanisms were suggested to be responsible for the cancer preventive potential of a Se-enriched diet and it is likely that all the proposed mechanisms act simultaneously depending on the specific cellular conditions (Whanger, 2004). Much attention has been given to the role of low molecular weight (LMW) Se-compounds in cancer prevention, showing that specific

\footnotetext{
Abbreviations: SeCys, selenocysteine; SeMCys, seleno-methylselenocysteine; SeMet, selenomethionine; $\gamma$-glu-SeMCys, gamma-glutamyl-seleno-methylselenocysteine; GSSeSG, seleno-di-glutathione; MeMet, methyl-methionine; GSH, glutathione; GSSG, di-glutathione; SMT, selenocysteine methyltransferase; MMT, methionine methyltransferase; SAM, S-adenosyl-methionine; DCM, dry cell matter; CTR, carbon dioxide transfer rate; SCX, strong cation exchange; SAX, strong anion exchange; ICP-MS, inductively coupled plasma-mass spectrometry.

* Corresponding author. Fax: +46317723801.

E-mail address: valeria.mapelli@chalmers.se (V. Mapelli).

1 The authors contributed equally to this work.
}

LMW Se-compounds able to supply a steady stream of mono-methylated Se-species have the highest potential in protection against cancer (Ip et al., 1991). Although methylselenol $\left(\mathrm{CH}_{3} \mathrm{SeH}\right)$ is considered the main element responsible for the bioactivity of LMW Se-metabolites, it is highly reactive; therefore, more stable precursors have been used for anti-carcinogenic studies. In particular, Se-methylselenocysteine (SeMCys), which is a direct precursor of $\mathrm{CH}_{3} \mathrm{SeH}$ (Fig. 1C), has been shown to be among the most effective Se-compounds in terms of anti-cancer potential (Dong et al., 2001; Ip et al., 2000b; Lee et al., 2006; Medina et al., 2001).

Plants capable to grow on soils with high Se content are the main source of Se-methylated LMW species. In fact, methylation of selenocysteine (SeCys) has been shown as one of the prerequisites for accumulating Se under less toxic forms, allowing plants to survive in seleniferous soils (Neuhierl et al., 1999). The majority of plants with high tolerance for Se belongs to the Astragalus genus, but also some edible plants such as broccoli (Brassica oleracea) and garlic (Allium sativum) are tolerant to Se and accumulate Se mainly in the form of SeMCys and gamma-glutamyl-seleno-methylselenocysteine ( $\gamma$-glu-SeMCys) (Block, 1996; Cai et al., 1995; Neuhierl et al., 1999; Shrift and Virupaksha, 1963; Trelease et al., 1960). Such peculiarities of Se-accumulator plants reside in the presence of a methyltransferase, which specifically methylates SeCys using S-adenosyl-methionine (SAM) or methyl-methionine (MeMet) as methyl donors (Lyi et al., 2005; Neuhierl and Bock, 1996; Neuhierl et al., 1999). 


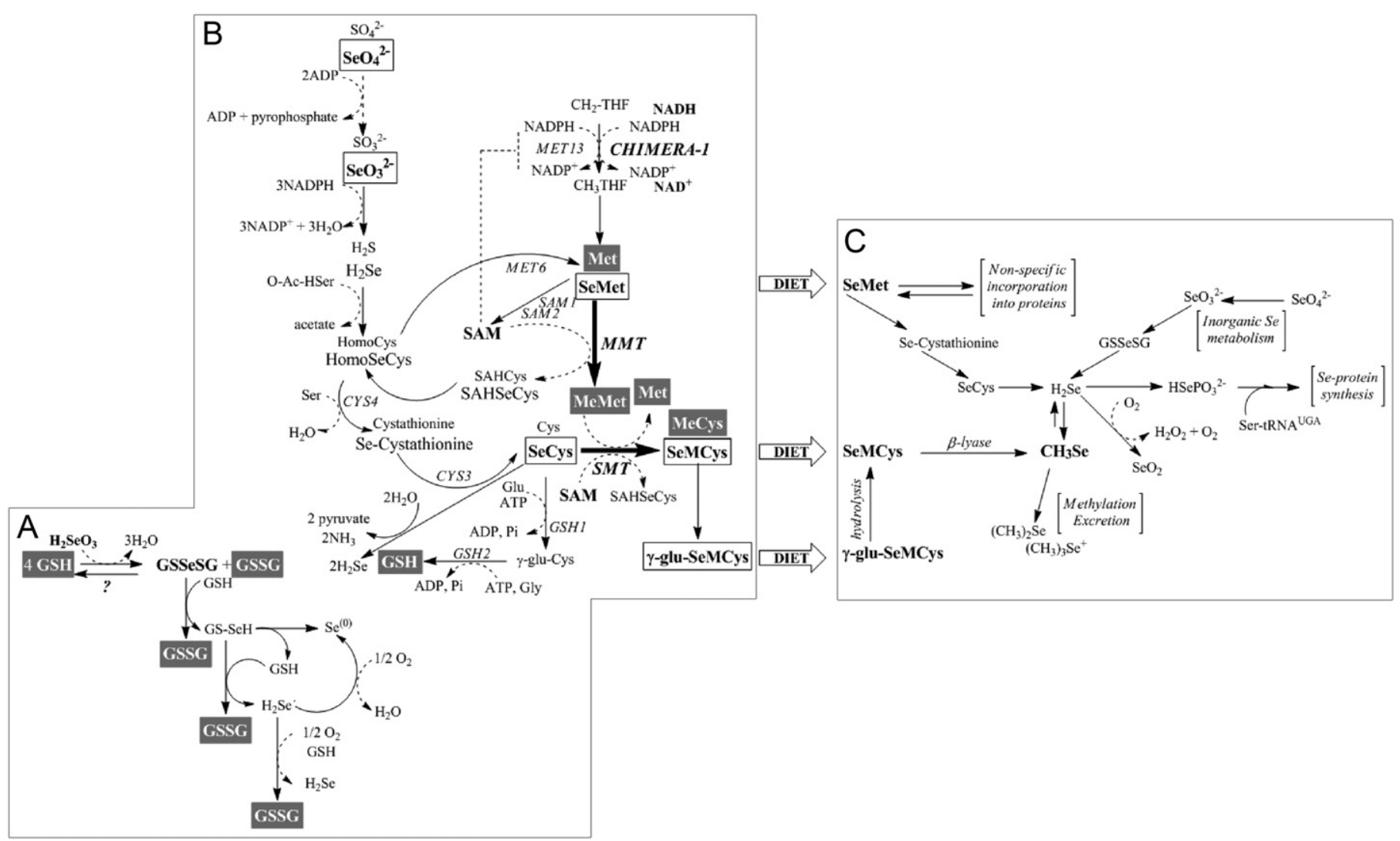

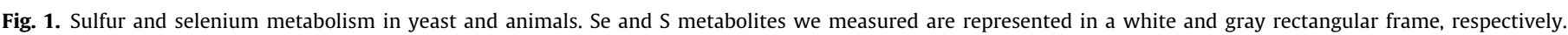

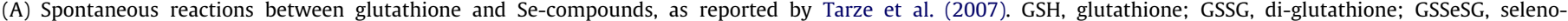

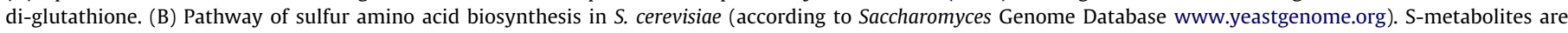

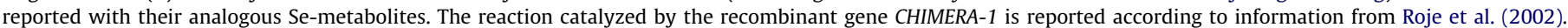

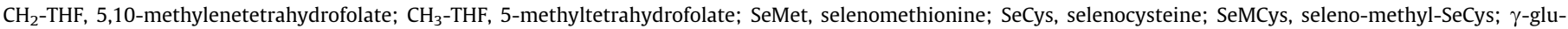

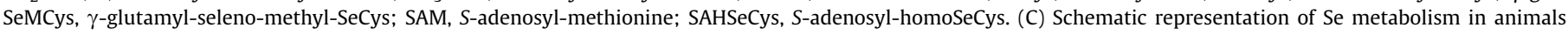
(adapted from (Rayman, 2005)).

Animal studies (Ip et al., 2000a; Kotrebai et al., 2000) have demonstrated that Se-enriched garlic containing $\gamma$-glu-SeMCys and SeMCys as major Se-components exerts a much higher cancer inhibition effect than Se-enriched yeast, wherein SeMet is the major Secompound (85\% on total Se). Furthermore, while Clark et al. (1996) observed cancer preventive effects owed to Se-enriched yeast administration, supplementation of pure SeMet during the Selenium and Vitamin E Cancer Prevention Trial (SELECT) did not result in observable beneficial effects (Lippman et al., 2009). Therefore, a better characterization of Se-enriched yeast is called for identifying less abundant Se-metabolites that are potentially more effective than SeMet in terms of cancer prevention. Thanks to the ease and efficiency of production and formulation, Se-enriched yeast is the most available food supplement up to date. Due to a high batch-tobatch variability of the Se-metabolome, analytical techniques are continuously under development toward the definition of a blueprint of LMW Se-species, aiming at determining causal relationships between the production process and the Se-metabolome and between the Se-metabolome and the effects in cancer prevention (Dernovics et al., 2009; Far et al., 2010). A few studies have been published on the establishment of bioprocesses that allow efficient uptake of Se and increase the rate of conversion of inorganic Se into Se-organic forms by yeast (Demirci and Pometto, 1999; Demirci et al., 1999), but no details on Se-speciation were reported within that context.

In this work, we show how coupling of metabolic engineering strategies to bioprocess optimization and the development of an analytical platform based on liquid chromatography coupled to
ICP-MS or ESI-MS/MS (Zha et al., 2009) was successful in achieving the production of Se-enriched yeast containing higher levels of SeMCys and $\gamma$-glu-SeMCys. To the best of our knowledge, no metabolic engineering attempts have been reported so far aiming at modifying the Se-metabolite profile of Se-enriched yeast toward higher levels of methylated Se-metabolites. In particular, we demonstrate how the balance between sulfur and selenium sources is critical for the uptake of Se by yeast and how this balance is important to modulate the toxic effects of Se on yeast; low sulfur levels are necessary for an efficient Se uptake, but an excessive decrease in $\mathrm{S}$ concentration is detrimental for yeast growth in the presence of Se. Furthermore, by construction and screening of several recombinant yeast strains, we demonstrate that the expression of a codon optimized SMT gene and high intracellular levels of SAM are essential to obtain significant improvement in SeMCys yields during fine tuned fed-batch cultivations. Further insight into yeast physiology in the presence of Se has also been gained, based on the determination of general physiological parameters and intracellular levels and dynamics of both selenium and sulfur metabolites.

\section{Materials and methods}

\subsection{Plasmid and strain construction}

All the plasmids used in this study are described in Table 1. YIplac and YEplac plasmids (Gietz and Sugino, 1988) were 
purchased from LGC Standards (Queens Road, Teddington, Middlesex, UK) and used for expression of heterologous genes in S. cerevisiae. Promoter and terminator sequences were amplified by PCR using high fidelity PCR enzyme mix (Fermentas, Vilnius, Lithuania) from genomic DNA preparation extracted from $S$. cerevisiae CEN.PK113-7D. Primers used for TEF2 promoter contained PstI restriction site (TEF2p_fw 5'-CTGCAGCCGCGACAAATTACCCATAAGG-3' and TEF2p_rv 5'-CTGCAGGTTAATTATAGTTCGTTGACCG-3'), as well as primers for $A D H 1$ promoter (ADH1p_fw 5'-CTGCAGCGGATATCCTTTTGTTGTTTCCG-3' and ADH1p_rev 5'-CTG CAGAGTTGATTGTATGCTTGGTATAGC-3'). Primers used for amplification of CYC1 terminator contained SaCI and EcoRI restriction sites (CYC1t_fw 5'-GAGCTCGGCCCCTTTTCCTTTGTC-3' and CYC1t_rev 5'-GAATTCGCAAATTAAAGCCTTCGAGC-3', respectively). The amplified products were inserted into YEplac and YIplac plasmids as reported in Table 1. BoSMT sequence coding for Smt from $B$. oleracea (kindly provided by Professor Li Li, Cornell University, USA) (Lyi et al., 2005) was amplified from plasmid pTriplEx_BoSMT

Table 1

Plasmids used in this study.

\begin{tabular}{lll}
\hline Plasmid & Features & Reference \\
\hline YEplac195 & URA3 & Gietz and Sugino (1988) \\
YCplac33 & URA3 & Gietz and Sugino (1988) \\
YEplac181 & LEU2 & Gietz and Sugino (1988) \\
YIplac128 & LEU2 & Gietz and Sugino (1988) \\
YIplac211 & URA3 & Gietz and Sugino (1988) \\
p413TEF & TEF1p-CYC1t & Mumberg et al. (1995) \\
YEplac195ADH & ADH1p-CYC1t & This study \\
YCplac33ADH & ADH1p-CYC1t & This study \\
YEplac181TEF & TEF2p-CYC1t, LEU2 & This study \\
YIplac128TEF & TEF2p-CYC1t, LEU2 & This study \\
YIplac211TEF & TEF2p-CYC1t, URA3 & This study \\
pTriplEx_BoSMT & & Lyi et al. (2005) \\
YEp_BoSMT & ADH1p-BoSMT-CYC1t, URA3 & This study \\
pUC_OptSMT & pUC57+OptSMT & GenScript Corp, USA \\
pUC_OptMMT & pUC57+OptMMT & GenScript Corp, USA \\
YEpOptSMT & TEF2p-OptSMT-CYC1t, LEU2 & This study \\
YEpOptMMT & TEF2p-OptMMT-CYC1t, URA3 & This study \\
YIpOptSMT & TEF2p-OptSMT-CYC1t, LEU2 & This study \\
YIpOptMMT & TEF2p-OptMMT-CYC1t, URA3 & This study \\
CHIMERA1-pVT103-U pVT103-U, CHIMERA1 & Roje et al. (2002) \\
YCT-CHI & TEF1p-CHIMERA1-CYC1t, HIS3 & This study \\
\hline
\end{tabular}

$\mathrm{p}$, promoter; $\mathrm{t}$, terminator. and cloned in between $\mathrm{XbaI}$ and SmaI restriction sites in YEplac195ADH and YCplac33ADH. The coding sequences of selenocysteine methyltransferase from A. bisulcatus (smtA) (Neuhierl et al., 1999) and methionine $S$-methyltransferase from $A$. thaliana (MMT) (Gene Bank NM_124359) were codon optimized for the expression in S. cerevisiae using JCat software (Grote et al., 2005). The synthetic genes (synthesized by GenScript, USA, Inc.) were called OptSMT and OptMMT. OptSMT fragment was excised from pUC_OptSMT and inserted between XbaI and SmaI sites in YIplac 128TEF obtaining the plasmid YIpOptSMT. OptMMT sequence was excised from pUC_OptMMT and inserted between XbaI and SmaI sites in YIplac211TEF obtaining the plasmid YIpOptMMT. The same cloning strategies were used for cloning of OptSMT and OptMMT into episomal plasmids. The CHIMERA-1-pVT103-U plasmid (Roje et al., 2002) was kindly provided by Professor Andrew D. Hanson (University of Florida, USA) and CHIMERA-1 gene was amplified by PCR using primers containing SpeI and Clal restriction sites (CHI_fw 5'-CACTAGTATGAAGATCACAGAAAAATTAGAGC-3' and CHI_rv 5'-GCATCGATTCAAGCAAAGACAGAGAAGATATC-3', respectively). The amplified fragment was inserted in the centromeric plasmid p413TEF (Mumberg et al., 1995) resulting in the plasmid YCT-CHI. Each new construct was sequenced to verify the absence of mutations (Eurofins MWG Operon, Ebersberg, Germany). Yeast transformation was performed with lithium acetate based method (Gietz and Woods, 2002). The correct integration of YIpOptSMT and YIpOptMMT plasmids was checked by PCR on isolated genomic DNA from selected colonies.

\subsection{Strains and media}

The $E$. coli strain DH-5 $\alpha$ was used as an intermediate host for cloning and plasmid amplification and was grown in LB medium (Sambrook and Russel, 2001) containing $100 \mathrm{mg} / \mathrm{l}$ ampicillin. All yeast strains used in this work are described in Table 2. S. cerevisiae strains used were CEN.PK113-7D, CEN.PK113-5D, CEN.PK111-32D, CEN.PK102-3A, CEN.PK113-7A, CEN.PK111-9A, and CEN.PK102-5B, kindly provided by Dr. Peter Kötter (Biozentrum, Frankfurt, Germany). Recombinant yeast strains were selected on solid yeast nitrogen based media supplemented with $20 \mathrm{~g} / \mathrm{l}$ glucose and, according to strain requirements, with $50 \mathrm{mg} / \mathrm{l}$ uracil, $50 \mathrm{mg} / \mathrm{l}$ leucine, and $50 \mathrm{mg} / \mathrm{l}$ histine (Formedium Ltd., Norwich, UK). Growth in shake flasks was performed in defined

Table 2

S. cerevisiae strains used in this study.

\begin{tabular}{|c|c|c|}
\hline Strain & Genotype & Source \\
\hline CEN.PK113-7D & MATa MAL2-8C, SUC2 & Peter Kötter ${ }^{\mathrm{a}}$ \\
\hline CEN.PK113-5D & MATa ura3-52, MAL2-8C, SUC2 & Peter Kötter \\
\hline CEN.PK111-32D & MATa leu2-3_112, MAL2-8C, SUC2 & Peter Kötter \\
\hline CEN.PK102-3A & MATa ura3-52, leu2-3_112, MAL2-8C, SUC2 & Peter Kötter \\
\hline CEN.PK113-7A & MATa his3 $\triangle$, MAL2-8C, SUC2 & Peter Kötter \\
\hline CEN.PK111-9A & MATa leu2-3_112, his3 $\triangle 1$, MAL2-8C, SUC2 & Peter Kötter \\
\hline CEN.PK102-5B & MATa ura3-52, leu2-3_112, his3 $\triangle 1$, MAL2-8C, SUC2 & Peter Kötter \\
\hline VM.hBoSMT & MATa MAL2-8C SUC2, YEp_BoSMT & This study \\
\hline VM.h0 & MATa MAL2-8C SUC2, pYEplac181TEF & This study \\
\hline VM.hS & MATa MAL2-8C SUC2, YEpOptSMT & This study \\
\hline VM.iS & MATa MAL2-8C SUC2, leu2::YIpOptSMT & This study \\
\hline VM.iShM & MATa MAL2-8C SUC2, leu2::YIpOptSMT, YEpOptMMT & This study \\
\hline VM.iSiM & MATa MAL2-8C SUC2, leu2::YIpOptSMT, ura3::YIpOptMMT & This study \\
\hline VM.0 & MATa MAL2-8C SUC2 p413 & This study \\
\hline VM.S & MATa MAL2-8C, SUC2, p413TEF, leu2::YIpOptSMT & This study \\
\hline VM.CS & MATa MAL2-8C, SUC2, leu2::YIpOptSMT, YCT-CHI & This study \\
\hline VM.CSM & MATa MAL2-8C, SUC2, leu2::YIpOptSMT, ura3::YIpOptMMT, YCT-CHI & This study \\
\hline
\end{tabular}

Abbreviations: h, high copy number; i, integrative; 0, negative control; S, SMT; M, MMT; C, CHIMERA-1.

a Max. von Laue Str. 9, Biozentrum N250, 60438 Frankfurt, Germany. 
mineral medium (Verduyn et al., 1992) buffered at pH 5.5 with $50 \mathrm{mM}$ potassium hydrogen phthalate (Hahn-Hägerdal et al., 2005) supplemented with $20 \mathrm{~g} / \mathrm{l}$ glucose; this medium is also referred to as S-regular medium in this work. Growth in shake flasks under sulfur shortage condition was performed in defined mineral medium based on Boer et al. (2003) containing $40 \mathrm{~g} / \mathrm{l}$ glucose, $4.0 \mathrm{~g} / 1 \mathrm{NH}_{4} \mathrm{Cl}, 0.05 \mathrm{~g} / \mathrm{l} \mathrm{MgSO}_{4} \cdot 7 \mathrm{H}_{2} \mathrm{O}, 3.0 \mathrm{~g} / 1 \mathrm{KH}_{2} \mathrm{PO}_{4}$, and $0.85 \mathrm{~g} / \mathrm{l} \mathrm{MgCl}_{2} \cdot 6 \mathrm{H}_{2} \mathrm{O}$ and buffered at $\mathrm{pH} 5.5$ with $50 \mathrm{mM}$ potassium hydrogen phthalate, vitamins and trace elements were as reported by Verduyn et al. (1992); this medium is referred here as $\mathrm{S}$-shortage medium. Media for growth in shake flasks in the presence of Se were supplemented with $20 \mathrm{mg} / \mathrm{l} \mathrm{Na}_{2} \mathrm{SeO}_{4}$.

\subsection{Batch and fed-batch cultivation conditions}

For batch cultivations, yeast strains were grown at $30{ }^{\circ} \mathrm{C}$ in 2.71 fermenters (Applikon Biotechnology B.V., Schiedam, Netherlands) and the total volume of the cultivation was $1.5 \mathrm{l}$. The $\mathrm{pH}$ was measured online and kept constant at 5.0 by automatic addition of $2 \mathrm{M} \mathrm{KOH}$ with the use of DASGIP fedbatch-pro ${ }^{\circledR}$ system provided with DASGIP Control and Multi Pump Module MP8 (DASGIP AG, Jülich, Germany). Stirrer speed was $800 \mathrm{rpm}$ and air flow was set at $1500 \mathrm{ml} / \mathrm{min}$. Dissolved oxygen tension was measured online and kept above $30 \%$ of air saturation with DASGIP Control system. The off-gas was cooled by a condenser connected to a cryostat set at $4{ }^{\circ} \mathrm{C}$; oxygen and carbon dioxide were measured with DASGIP off-gas analyzer GA4. For fed-batch cultivations, the batch phase was run in $11 \mathrm{~S}$-shortage medium described above, supplemented with $20 \mathrm{~g} / \mathrm{l}$ glucose. Such medium was defined in order to achieve complete depletion of glucose and sulfate at the same time, so that glucose and sulfate could be kept at limiting concentration during the following feeding phase. At the end of the batch phase, when both glucose and sulfate were completely depleted, an exponential feed of medium was started at a rate corresponding to a specific growth rate of $0.1 \mathrm{~h}^{-1}$ (Nielsen et al., 2002). The medium supplemented during the fed-batch phase was prepared in order to achieve a dual limitation of glucose and sulfate and its composition was defined according to Egli and Zinn (2003); further details can be found in the Results section and Table 3. The composition of the medium fed during the fed-batch phase was $200 \mathrm{~g} / \mathrm{l}$ glucose, $1.6 \mathrm{~g} / \mathrm{l} \mathrm{MgSO}{ }_{4} \cdot 7 \mathrm{H}_{2} \mathrm{O}$ or $1.06 \mathrm{~g} / \mathrm{l} \mathrm{MgSO}{ }_{4} \cdot 7 \mathrm{H}_{2} \mathrm{O}$, and $0.107 \mathrm{~g} / \mathrm{l} \mathrm{Na} \mathrm{SeO}_{4}$ when cultivations were run in the presence of selenium source. The $\mathrm{pH}$ was kept constant at 5.0 by automatic addition of $10 \%(\mathrm{v} / \mathrm{v}) \mathrm{NH}_{3}$. After $20 \mathrm{~h}$ the addition of medium was interrupted and cells were harvested by centrifugation at $4000 \mathrm{rpm}$ at $4{ }^{\circ} \mathrm{C}$.

\subsection{Analysis of extracellular metabolites and residual sulfate}

Culture supernatants were obtained after centrifugation of samples from the fermenter at $14,000 \mathrm{rpm}$ at $4{ }^{\circ} \mathrm{C}$ and stored at

Table 3

Predicted boundaries for dual-substrate (carbon and sulfur) limited growth.

\begin{tabular}{lcccl}
\hline $\begin{array}{l}\text { Growth } \\
\text { conditions }\end{array}$ & $Y_{\mathrm{X} / \mathrm{C}^{\mathrm{a}}}$ & $Y_{\mathrm{X} / \mathrm{SO}_{4}^{-}}{ }^{\mathrm{b}}$ & $\begin{array}{l}\text { Boundary predicted } \\
\left.\text { (ratio Glc/SO}{ }^{2-}\right)^{\mathrm{c}}\end{array}$ & $\begin{array}{l}\text { Source of } \\
\text { experimental data }\end{array}$ \\
\hline $\begin{array}{l}\text { C-limited } \\
\text { S-limited }\end{array}$ & 0.5 & 30 & 60 & $\begin{array}{l}\text { Boer et al. (2003) } \\
\text { Boer et al. (2003) }\end{array}$ \\
\hline
\end{tabular}

${ }^{\mathrm{a}}$ Biomass yield on glucose.

b Biomass yield on sulfate.

${ }^{c}$ Calculated according to Egli and Zinn (2003), where $Y_{\mathrm{X} / \mathrm{SO}_{4}^{2}-} / Y_{\mathrm{X} / \mathrm{C}}$ under C-limitation and $Y_{\mathrm{X} / \mathrm{SO}_{4}^{-}} / Y_{\mathrm{X} / \mathrm{C}}$ under S-limitation give the lower and the higher ratio, respectively, of $\mathrm{Glc} / \mathrm{SO}_{4}^{2-}$ concentration in the feed for which both glucose and sulfate limitations were occurring at the same time.
$-20{ }^{\circ} \mathrm{C}$ until analysis. Concentrations of glucose, ethanol, glycerol, acetate, and pyruvate were determined by HPLC (Ultimate 3000, Dionex Corp., Sunnyvale, USA) fitted with Aminex ${ }^{\circledR}$ HPX$87 \mathrm{H}$ column (Bio-Rad Laboratories, Inc.) kept at $45^{\circ} \mathrm{C}$ and using $5 \mathrm{mM} \mathrm{H}_{2} \mathrm{SO}_{4}$ as mobile phase at a flow rate of $0.6 \mathrm{ml} / \mathrm{min}$. All compounds were detected by a refractive index detector RI-101 and variable wavelength detector VWD 3100 (Dionex Corp., Sunnyvale, USA) at a fixed wavelength of $210 \mathrm{~nm}$. The concentration of sulfate was measured by a turbidimetric method based on precipitation of sulfates as $\mathrm{BaSO}_{4}$ after reacting with $\mathrm{BaCl}_{2}$ under acidic conditions (Treadwell, 1924). The turbidity of the samples was measured spectrophotometrically at $550 \mathrm{~nm}$ and the concentration of sulfate was derived from a 6-point calibration curve obtained using known concentrations of $\mathrm{MgSO}_{4}$.

\subsection{Intracellular metabolite extraction}

The pure methanol method was used for extraction of metabolites from yeast (Villas-Boas et al., 2005). Metabolites extracted in $100 \%$ methanol were diluted in milliQ water to a methanol concentration $\leq 25 \%(\mathrm{v} / \mathrm{v})$. Samples were frozen in liquid nitrogen and then lyophilized using a freeze drier Christ alpha 2-4 LSC (Martin Christ Gefriertrocknungsanlagen $\mathrm{GmbH}$, Osterode am Harz, Germany). After lyophilization, metabolites were dissolved in $1.4 \mathrm{ml}$ of $25 \%(\mathrm{v} / \mathrm{v})$ methanol and transferred to $2 \mathrm{ml}$ sterile tubes. The second step of lyophilization was performed and samples were stored at $-80^{\circ} \mathrm{C}$ until analysis.

\subsection{Analysis of intracellular Se and S metabolites}

Instrumental operating conditions were the same as in Kápolna et al. (2009), with some modifications as follows. An Agilent 1100 liquid chromatography (LC) system (Agilent, Santa Clara, USA) was used for hyphenation with the mass spectrometers for analysis of metabolites. Extracted lyophilized metabolites were re-suspended in $150 \mu \mathrm{l} 0.25 \%$ formic acid (Merck KGaA, Darmstadt, Germany) and further diluted with $0.25 \%$ formic acid before analysis with the strong cation exchange system (SCX) for selenium speciation with the inductively coupled plasma-mass spectrometric (ICP-MS) detection and for targeted sulfur metabolite determination with a triple quadrupole mass spectrometry (ESI-MS/MS) detection. The ICP-MS instrument used was a quadrupole-based Perkin Elmer (Glendale, Canada) Sciex Elan 6100 equipped with a dynamic reaction cell (DRC), while the triple quadrupole mass spectrometer was a Quattro Micro (Waters, Milford, USA) equipped with an ESI ion source operated in positive mode. Nitrogen was used as nebulizer, auxiliary, and collision gas. Detections were performed in MRM mode. The cation exchange separation was achieved with IonoSpher 5C column $(150 \mathrm{~mm} \times 2 \mathrm{~mm}, 5 \mu \mathrm{m})$ from Varian (Palo Alto, USA) protected with SCX SecurityGuard $(4.0 \mathrm{~mm} \times 2.0 \mathrm{~mm})$ from Phenomenex (Torrance, USA). The outlet of the column was connected to a micro-splitter (Upchurch, Oak Harpor, WA), splitting the flow 1:1 between the ICP-MS and the ESI-MS/MS. All connections were PEEK tubing (ID $65 \mu \mathrm{m}$ ). The sample-introduction system of the ICP-MS consisted of a pneumatic nebulizer and a spray chamber. Methane at optimized flow rate was used as collision gas in the DRC of the ICP-MS system to eliminate argonbased polyatomic interferences on ${ }^{80} \mathrm{Se}$.

\subsection{Analysis of residual extracellular inorganic selenium}

Samples of cell-free cultivation broth were stored at $-20{ }^{\circ} \mathrm{C}$ until analysis. An aliquot was diluted with the mobile phase and analyzed in the strong anion exchange system (SAX) with ICP-MS detection. Instrumental operating conditions were the same as 
in Kápolna et al. (2009), with some modifications as follows. The SAX separation system was hyphenated with a Perkin Elmer 200 HPLC pump equipped with a Waters $717_{\text {PLus }}$ autosampler (Waters Corp.). Separation of the inorganic selenium forms was achieved with an ION-120 column $(120 \mathrm{~mm} \times 4.6 \mathrm{~mm}, 5 \mu \mathrm{m})$ from Transgenomic (Glasgow, UK) protected with matching guard cartridge. The outlet of the column was connected directly to the ICP-MS.

\subsection{Analysis of total selenium content in dry cell biomass}

Cells were harvested by centrifugation at $4000 \mathrm{rpm}$ for $5 \mathrm{~min}$, the supernatant was removed, and cells were washed with sterile deionized water at $4000 \mathrm{rpm}$ for $5 \mathrm{~min}$. Biomass was freeze dried and stored at $-20{ }^{\circ} \mathrm{C}$ until analysis. Prior to the total selenium analysis by ICP-MS, samples were digested by concentrated nitric acid using a microwave system equipped with quartz vessels operated at a maximum pressure and temperature of 70 bar and $250{ }^{\circ} \mathrm{C}$ (Multiwave, Anton Paar, Graz, Austria) (Kápolna et al., 2009), respectively. For extraction of Se-compounds from dried biomass, $0.250 \mathrm{~g}$ of dried biomass was dissolved in milliQ water and exposed to ultrasonication with the help of an ultrasonic probe Microson XL 2000 ultrasonic liquid processor (New York, USA), tip diameter $1 / 4^{\prime \prime}$ (output $7 \mathrm{~W}$ for $1.5 \mathrm{~min}$ ), and sample extracts were further diluted before chromatographic analyses.

\subsection{SeCys methyltransferase activity assay}

Cells were harvested and re-suspended in $0.1 \mathrm{M}$ phosphate buffer, $\mathrm{pH} 7.5,2 \mathrm{mM} \mathrm{MgSO} 4 \cdot 7 \mathrm{H}_{2} \mathrm{O}$, and in $1 \mathrm{mM}$ dithiothreitol. Cells were broken by the addition of acid washed glass beads followed by ten cycles of vortexing at $4{ }^{\circ} \mathrm{C}$ ( $1 \mathrm{~min}$ per cycle). Cell extracts were clarified by centrifugation and total protein content was determined according to the Bradford method, using Bio-Rad protein assay reagent (Bio-Rad Laboratories, Inc.). Activity of recombinant AbSMT was assayed using the methods previously described (Lyi et al., 2005; Neuhierl and Bock, 1996). In short, the reaction mixture ( $50 \mu$ l total volume) consisted of $50 \mathrm{mM}$ sodium citrate, $\mathrm{pH}$ 7.0, $10 \mathrm{mM}$ magnesium acetate, $5 \mathrm{mM}$ 1,4-dithiothreitol, $10 \mu \mathrm{l}$ of protein extract, and $1 \mathrm{mM}$ selenocysteine (pre-reduced for at least $30 \mathrm{~min}$ at $25{ }^{\circ} \mathrm{C}$ with a 10 -fold molar excess of sodium borohydride). The reaction was started by addition of $1 \mathrm{mM}$ SAM and incubated at $30{ }^{\circ} \mathrm{C}$ for 5 or $40 \mathrm{~min}$ and analyzed for the conversion of SeCys into SeMCys via SCX-ESI-MS/MS as described above.

A

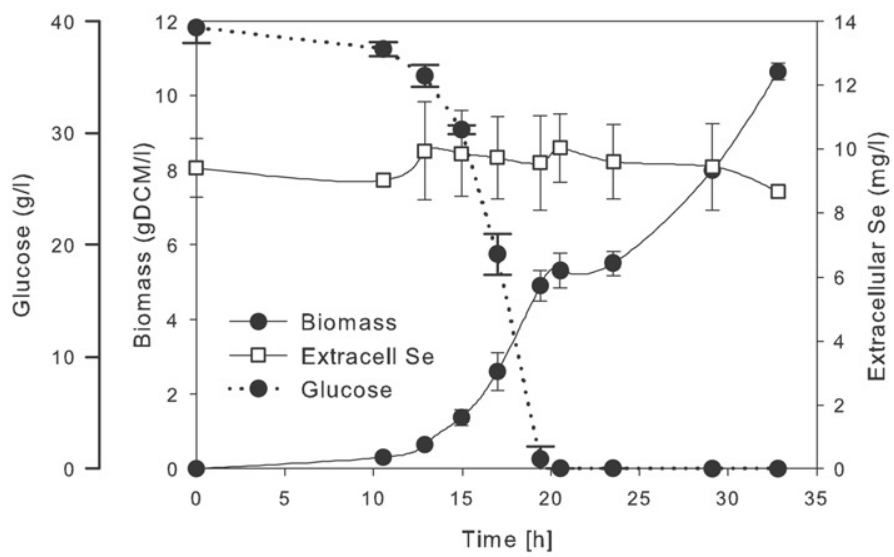

\section{Results}

\subsection{Establishing batch cultivation conditions for efficient SE uptake by yeast}

In order to establish the optimal growth conditions allowing an efficient uptake of Se by yeast in batch cultivations using glucose as the main carbon source, two main factors were taken into account. First, the source and amount of Se in the medium and second the possible influence of sulfate concentration in the growth medium on Se uptake were investigated. Sodium selenite $\left(\mathrm{Na}_{2} \mathrm{SeO}_{3}\right)$ (patent no. HK1078611 (A1)) and sodium selenate $\left(\mathrm{Na}_{2} \mathrm{SeO}_{4}\right)$ are the Se sources typically used for Se-enriched yeast production. $\mathrm{Na}_{2} \mathrm{SeO}_{4}$ was our choice as Se source because $\mathrm{Na}_{2} \mathrm{SeO}_{3}$, unlike $\mathrm{Na}_{2} \mathrm{SeO}_{4}$, can react with reducing sugars (e.g. glucose) forming elemental $\mathrm{Se}$, which is not bioavailable. In addition, $\mathrm{Na}_{2} \mathrm{SeO}_{4}$ has been shown to allow higher levels of organically bound $\mathrm{Se}$ in Se-enriched yeast, compared to $\mathrm{Na}_{2} \mathrm{SeO}_{3}$ (Demirci and Pometto, 1999). When using sulfate $\left(\mathrm{SO}_{4}^{2-}\right.$ ) as sulfur source in growth media, $\mathrm{S}: \mathrm{Se}$ ratio plays a critical role in determining Se uptake and building of biomass (Demirci and Pometto, 1999). Therefore, cells were grown under two different $\mathrm{SO}_{4}^{2-}$ concentrations (3.8 g/l for S-regular and $0.02 \mathrm{~g} / \mathrm{l}$ for S-shortage) and in the presence of different concentrations of $\mathrm{Na}_{2} \mathrm{SeO}_{4}$ (from 10 to $100 \mathrm{mg} / \mathrm{l}$ ). At $\mathrm{Na}_{2} \mathrm{SeO}_{4}$ levels higher than $20 \mathrm{mg} / \mathrm{l}$, cells were poorly growing under S-shortage due to Se toxicity (data not shown). Interestingly, only under S-shortage Se was completely consumed, whereas no significant Se uptake was detected in S-regular medium (Fig. 2A and B). Consistently, $\mathrm{Na}_{2} \mathrm{SeO}_{4}$ exerted toxic effect on yeast only when growing under S-shortage. The specific growth rate was drastically affected, dropping from 0.39 to $0.1 \mathrm{~h}^{-1}$ in the presence of $20 \mathrm{mg} / \mathrm{l} \mathrm{Na}_{2} \mathrm{SeO}_{4}$ (i.e. $0.015 \mathrm{~g} / \mathrm{l}$ $\mathrm{SeO}_{4}^{2-}$ ) (Fig. 2A and B).

\subsection{Construction of recombinant yeast strains}

On analysis of Se-metabolite profile of Se-enriched yeast (Kotrebai et al., 2000), SeMCys has been found to account for $0.5 \%$ of the total non-protein-bound Se. In order to increase the intracellular levels of SeMCys, the SMT gene from B. oleracea (BoSMT) (Lyi et al., 2005) encoding a SeCys methyltransferase was expressed in S. cerevisiae on a high copy plasmid (YEp_BoSMT, Tables 1 and 2). No intracellular SeMCys was detectable throughout the batch cultivations under S-shortage with $20 \mathrm{mg} / \mathrm{l} \mathrm{Na}_{2} \mathrm{SeO}_{4}$, and in vitro assay for SeCys

B

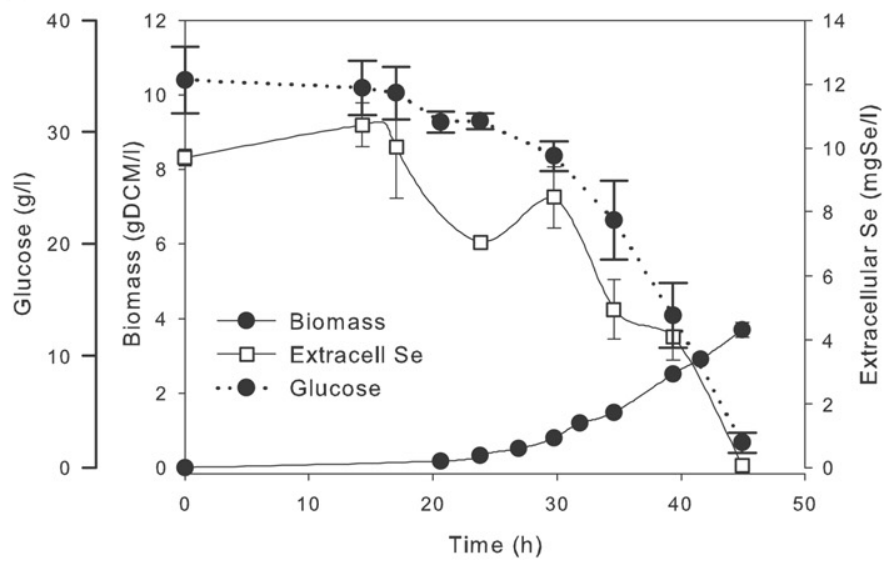

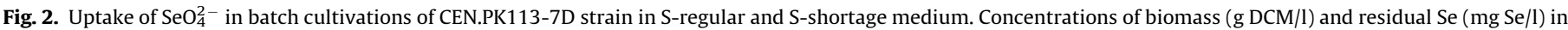

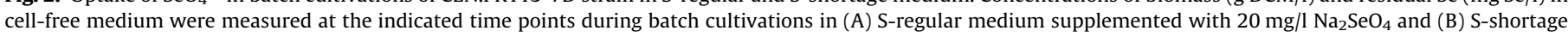

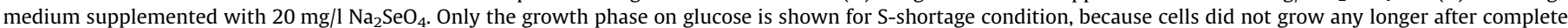
consumption of glucose. Data shown are mean values of three individual cultivations. 
methyltransferase activity showed very low Smt activity in protein crude extracts (data not shown).

Since Smt from A. bisulcatus is known to have higher specific activity than BoSmt (Lyi et al., 2005; Neuhierl and Bock, 1996), the cDNA sequence of the smtA gene from A. bisulcatus (Neuhierl and Bock, 1996; Neuhierl et al., 1999) was codon optimized for expression in $S$. cerevisiae, and the optimized gene optSMT was expressed in yeast both on a high copy (YEpOptSMT) and on an integrative plasmid (YIpOptSMT), resulting in the recombinant strains VM.hS and VM.iS, respectively (Tables 1 and 2).

The functional expression of optSMT in yeast was tested by assaying protein crude extracts for SeCys methyltransferase activity in vitro. Protein crude extracts were from VM.hS and VM.iS strains grown in batch under S-shortage in the presence or absence of $\mathrm{Na}_{2} \mathrm{SeO}_{4}$. The in vitro assay showed that Smt was functionally expressed by yeast regardless of the presence of $\mathrm{Na}_{2} \mathrm{SeO}_{4}$ in the growth medium and that the conversion of SeCys into SeMCys ranged between $15 \%$ and $20 \%$ (Fig. 3A), in a comparable way to Neuhierl et al. (1999), where the maximal conversion reported was $20-25 \%$. The assay demonstrated that the level of conversion of SeCys was not dependent on the copy number of optSMT, as no significant differences were observed comparing protein extracts from VM.hS and VM.iS. VM.iS was selected for further experiments, as strains carrying heterologous gene(s) integrated in the genome are typically more stable than the ones carrying such gene(s) on episomal plasmids.

Although optSMT was functionally expressed, no SeMCys biosynthesis could be detected in batch cultivations supplemented with $\mathrm{Na}_{2} \mathrm{SeO}_{4}$ under S-shortage (Fig. 3B). As one of the reasons for no detection of SeMCys might be SMT low affinity for SAM as methyl donor, the possibility to further engineer yeast for biosynthesis of methyl-methionine (MeMet) was considered. In fact, Smt from A. bisulcatus had shown 100\% SeCys conversion into SeMCys when using MeMet versus 20-25\% conversion when using SAM as methyl donor (Neuhierl et al., 1999). Therefore, the cDNA sequence of the methionine methyltransferase gene (MMT) from A. thaliana was codon optimized for expression in yeast and synthesized, resulting in optMMT, which was cloned both into high copy and integrative plasmids (YEpOptMMT and YIpOptMMT, respectively, Table 1) and expressed in VM.iS strain, resulting in VM.iShM and VM.iSiM strains, respectively (Table 2). However, none of the two strains co-expressing optSMT and optMMT were able to synthesize SeMCys at detectable levels under S-shortage supplemented with $20 \mathrm{mg} / \mathrm{l} \mathrm{Na}{ }_{2} \mathrm{SeO}_{4}$ (data not shown). These results led to the hypothesis that the levels of SAM were too low to effectively sustain the biosynthesis of SeMCys and MeMet to high levels.

\subsection{Intracellular levels of SAM change according to yeast growth phase}

The yeast MET13 gene, encoding a NADPH-dependent methylenetetrahydrofolate reductase (MTHFR), is known to be feedback inhibited by SAM. This inhibition can be released by substituting the endogenous C-terminal portion with the C-terminal of the homologous MTHFR gene from A. thaliana: the resulting CHIMERA-1 gene has been characterized and higher levels of SAM have been shown in a yeast strain expressing CHIMERA-1 (Lu et al., 2007; Roje et al., 2002). A preliminary characterization of the CHIMERA-1 expression within the genetic background of the yeast strains used in this work (i.e. CEN.PK strains) confirmed a general increase in SAM intracellular levels when compared to SAM levels in the control strain (data not shown). Interestingly, in batch cultivations intracellular SAM levels were even higher after
A
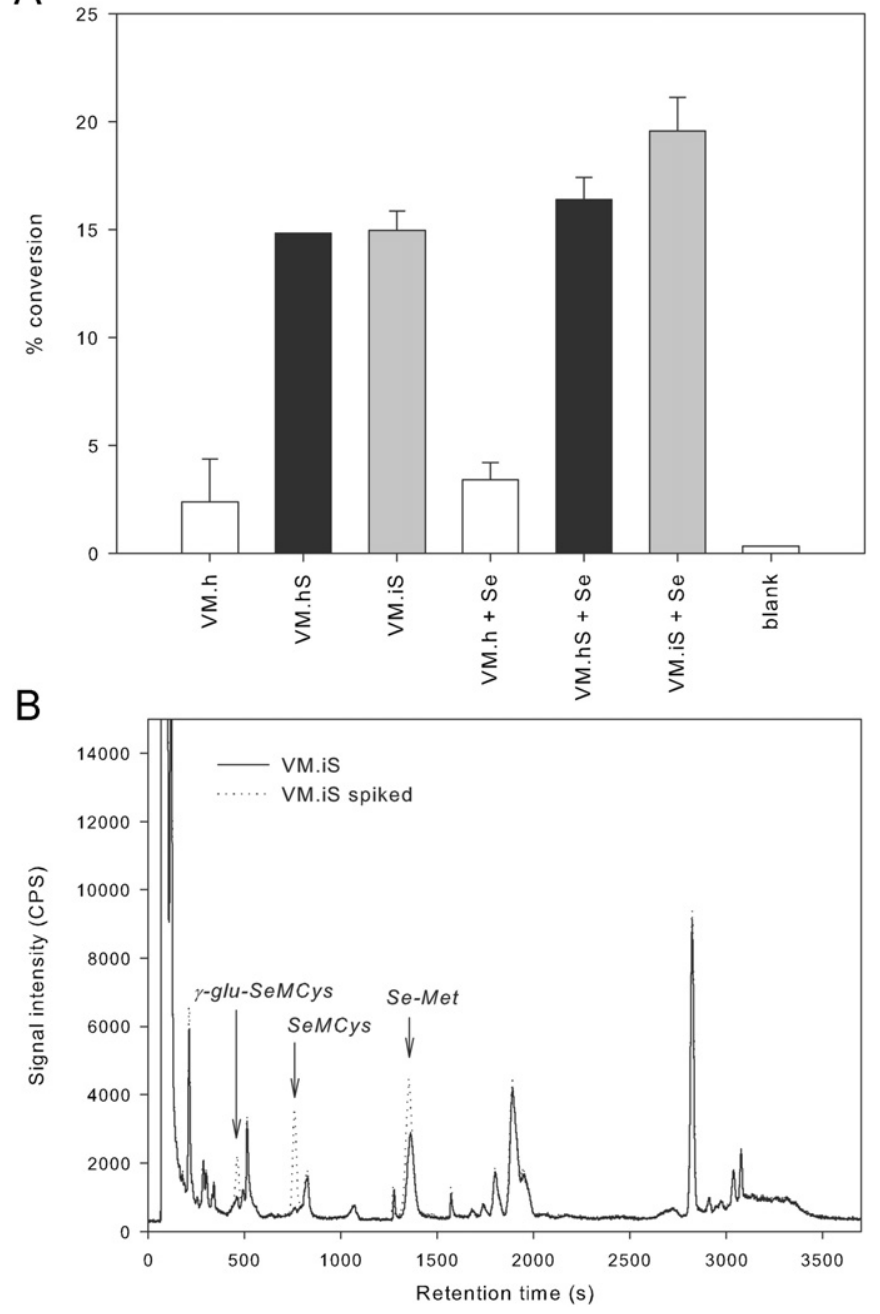

Fig. 3. In vitro enzymatic conversion of SeCys to SeMCys and in vivo SeMCys biosynthesis. (A) Yeast strains carrying the high copy plasmid YEpOptSMT (VM.hS) or with optSMT gene integrated in the genome (VM.iS) were grown without supplementation of $\mathrm{Se}$ or in the presence of $20 \mathrm{mg} / \mathrm{l} \mathrm{Na} \mathrm{NeO}_{4}(+\mathrm{Se})$ under S-shortage. The strain carrying YEplac195TEF (VM.h0) was used as negative control. The blank reaction mixture contained a crude protein extract from a yeast strain expressing optSMT and all other components except for SAM. Conversion of SeCys to SeMCys was tested on crude protein extracts in the presence of $1 \mathrm{mM}$ SeCys and $1 \mathrm{mM} \mathrm{SAM}$ for $40 \mathrm{~min}$ at $30{ }^{\circ} \mathrm{C}$ and normalized on the total protein concentration. Detection of SeCys and SeMCys was carried out via SCX-ESI-MS/MS. (B) Analysis of intracellular Se-metabolites from VM.iS grown under sulfur shortage medium supplemented with $20 \mathrm{mg} / \mathrm{l} \mathrm{Na}_{2} \mathrm{SeO}_{4}$. Samples were spiked (dotted line) with $\gamma$-glu-SeMCys, SeMCys and Se-Met and analyzed via SCX-ICP-MS.

the diauxic shift (data not shown), that is, when yeast undergoes a fully respiratory metabolism.

\subsection{Bioprocess setup and optimization}

The uptake and conversion of Se by yeast can be influenced by several factors including the form of Se fed through the medium, the rate of Se supplementation, and the ratio between the concentration of sulfur and selenium (S:Se) in the growth medium (Demirci and Pometto, 1999; Demirci et al., 1999). In particular, it has been demonstrated that using $\mathrm{Na}_{2} \mathrm{SeO}_{4}$ as $\mathrm{Se}$ source favors the conversion of inorganic Se into organically bound $\mathrm{Se}$, if compared to the use of $\mathrm{Na}_{2} \mathrm{SeO}_{3}$, which results in higher Se concentration in the biomass, but lower concentration 
of organically bound Se (Demirci and Pometto, 1999). Furthermore, the gradual addition of $\mathrm{Na}_{2} \mathrm{SeO}_{4}$ during fermentation has been shown to result in a less toxic effect on yeast and higher conversion rate into organic Se forms, when compared to the addition of $\mathrm{Na}_{2} \mathrm{SeO}_{4}$ as a single dose (Demirci et al., 1999). Interestingly, also the $S: S e$ ratio in the growth media has been determined as a very important factor tuning both the toxicity of Se and its metabolism toward the biosynthesis of organic Se-compounds (Demirci and Pometto, 1999). Similarly, we show that the levels of $\mathrm{SO}_{4}^{2-}$ during batch fermentations were crucial for an efficient uptake of $\mathrm{SeO}_{4}^{2-}$ (Fig. 2A and $\mathrm{B}$ ) and specifically that $\mathrm{SeO}_{4}^{2-}$ uptake occurs only in the presence of limiting $\mathrm{SO}_{4}^{2-}$ concentrations.

Therefore, a fermentation process in which both: $\mathrm{SO}_{4}^{2-}$ and glucose were limiting at the same time was desirable, the former to allow an effective Se uptake and the latter to trigger the biosynthesis of SAM to higher levels in strains expressing $\mathrm{CHI}$ MERA-1 gene. At the same time, high cell density was desirable, since the process was designed in view of possible scale-up. A general scheme of the fed-batch bioprocess designed is reported in Fig. 4. The batch phase was run with S-shortage medium supplemented with $20 \mathrm{~g} / \mathrm{l}$ glucose, as preliminary fermentations

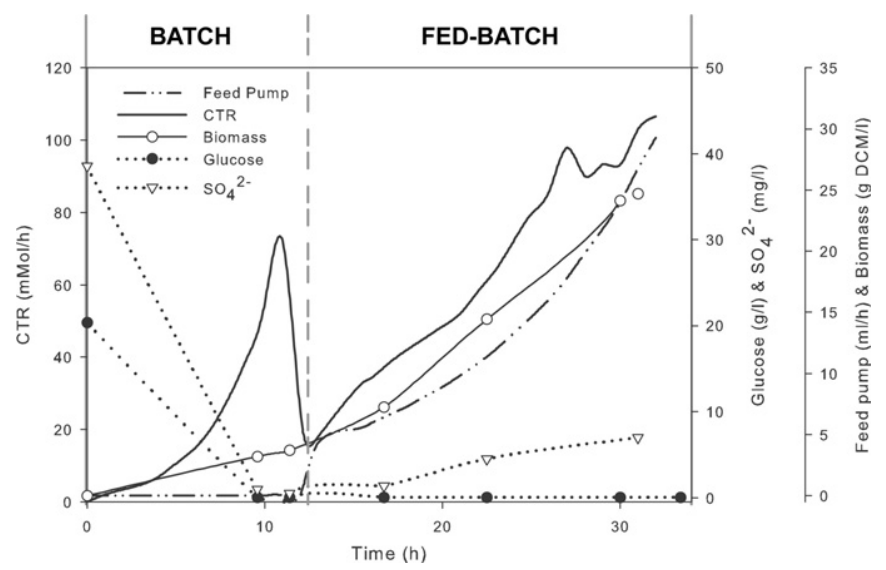

Fig. 4. Schematic representation of dual limited fed-batch of strain VM.0. Data are from one of the cultivations run with a Glc: $\mathrm{SO}_{4}^{2-}$ ratio equal to 320.5 in the fedbatch phase; the feeding medium contained $0.107 \mathrm{~g} / 1 \mathrm{Na}_{2} \mathrm{SeO}_{4}$. When the carbon dioxide transfer rate (CTR) was equal to $30 \mathrm{mMol} / \mathrm{h}$ on the descending edge, the feed pump automatically started and kept pumping fresh medium for $20 \mathrm{~h}$ with exponential profile calculated according to Nielsen et al. (2002) in order to sustain a $\mu=0.1 \mathrm{~h}^{-1}$. Dry cell matter, residual glucose and residual sulfate were measured at indicated time points. When the feeding pump started, both glucose and sulfate were completely consumed and their level was kept at limiting concentration throughout the whole fed-batch phase. The slight increase in the sulfate can be considered an artifact deriving from noise detected with the analytical method used. showed that yeast consumed $20 \mathrm{~g} / 1$ glucose while completely consuming $0.02 \mathrm{~g} / \mathrm{l} \mathrm{SO}_{4}^{2-}$. After complete depletion of glucose and $\mathrm{SO}_{4}^{2-}$, a feed containing glucose, $\mathrm{MgSO}_{4}$, and $\mathrm{Na}_{2} \mathrm{SeO}_{4}$ was provided continuously following an exponential profile able to sustain the yeast specific growth rate of $0.1 \mathrm{~h}^{-1}$. The feed composition was defined accordingly (Boer et al., 2003; Egli and Zinn, 2003), and the physiological values used for the calculations are reported in Table 3. We chose Glc: $\mathrm{SO}_{4}^{2-}$ equal to $483.5 \mathrm{~g} / \mathrm{g}$ (i.e. the mid-value between the two boundaries), which resulted in a dual limited process, as no residual glucose and sulfate could be detected (data not shown). Yields of biomass and ethanol (Table 4) also indicated that fermentative metabolism was prevented when running the fermentation without the addition of $\mathrm{Na}_{2} \mathrm{SeO}_{4}$ to the feed.

When $\mathrm{Na}_{2} \mathrm{SeO}_{4}$ was added to the feed at $0.107 \mathrm{~g} / \mathrm{l}$ (PharmaNord, Vojens, Denmark, personal communication), analysis of extracellular residual Se revealed that most of the added Se was consumed, resulting in $1061 \pm 43 \mu \mathrm{g} \mathrm{Se} / \mathrm{g}$ dry cell biomass. However, traces of residual $\mathrm{Se}(\mathrm{VI})$ (i.e. $\mathrm{SeO}_{4}^{2-}$ ) could still be found, indicating that Se uptake was not complete. Furthermore, in the presence of $\mathrm{Na}_{2} \mathrm{SeO}_{4}$ the yield of biomass decreased from 0.4 to $0.25 \mathrm{~g} / \mathrm{g}$ and ethanol production was detected (Table 4). These data suggested that the added amount of Se exerted toxic effect on yeast, as the yield of biomass was drastically affected. Due to the crucial role that S:Se ratio could play, the composition of the feed was changed by increasing the concentration of $\mathrm{MgSO}_{4}$ with the aim of buffering the toxicity of Se, nonetheless considering to maintain the Glc: $\mathrm{SO}_{4}^{2-}$ ratio within the calculated boundaries (Table 3). Therefore, $\mathrm{MgSO}_{4}$ concentration was increased to get a Glc: $\mathrm{SO}_{4}^{2-}$ ratio equal to $320.5 \mathrm{~g} / \mathrm{g}$. As reported in Table 4, no ethanol formation could be detected both in the presence and in the absence of $\mathrm{Na}_{2} \mathrm{SeO}_{4}$ in the feed and no significant difference in biomass yield was observed between the two conditions. All recombinant strains were characterized under such conditions and it is worth noticing that no big differences could be observed in terms of biomass yield, ethanol formation, and amount of total Se per $\mathrm{g}$ of biomass (Table 4 ). The biomass yield was only slightly affected by the presence of $\mathrm{Na}_{2} \mathrm{SeO}_{4}$.

\subsection{Selenium is fully consumed, metabolized, and partly excreted}

Analysis of Se content in the cell-free fermentation broth throughout the feeding phase of the cultivations showed that under the established conditions (i.e. feeding containing Glc: $\mathrm{SO}_{4}^{2-}$ equal to 320 and $0.107 \mathrm{~g} / 1 \mathrm{Na}_{2} \mathrm{SeO}_{4}$ ) the supplied Se was almost fully consumed (Fig. 5A): traces of $\mathrm{SeO}_{4}^{2-}$ (i.e. $\mathrm{Se}(\mathrm{VI})$ ) were still detected in the fermentation broth $2-3 \mathrm{~h}$ after the feed of $\mathrm{Na}_{2} \mathrm{SeO}_{4}$ started, but nearly no $\mathrm{Se}(\mathrm{VI})$ could be found thereafter (Fig. 5A and B). Surprisingly, after $\sim 7 \mathrm{~h}$ what was thought to be

Table 4

Cultivation conditions and physiological parameters of fed-batch cultivations.

\begin{tabular}{|c|c|c|c|c|c|}
\hline Strain & $\mathrm{SO}_{4}^{2-}: \mathrm{SeO}_{4}^{2-}(\mathrm{g} / \mathrm{g})$ & Glc:SO ${ }_{4}^{2-}(\mathrm{g} / \mathrm{g})$ & $\begin{array}{l}Y_{X / S} \text { in feeding } \\
\text { phase }^{a}\end{array}$ & $\begin{array}{l}\text { Residual EtOH } \\
(\mathrm{g} / \mathbf{l})^{\mathbf{b}}\end{array}$ & $\begin{array}{l}\mu \mathrm{g} \mathrm{Se} / \mathrm{g} \\
\mathrm{DCM}\end{array}$ \\
\hline VM.0 w/o Se & - & 483.5 & $0.40 \pm 0.01$ & $0.36 \pm 0.17$ & - \\
\hline VM.0 & 5.1 & 483.5 & $0.25 \pm 0.01$ & $7 \pm 0.4$ & $1062 \pm 43$ \\
\hline CTRL w/o Se & - & 320.5 & $0.64 \pm 0.06$ & - & - \\
\hline VM.0 & 7.7 & 320.5 & $0.57 \pm 0.03$ & - & $458 \pm 57$ \\
\hline VM.S & 7.7 & 320.5 & $0.60 \pm 0.02$ & - & $397 \pm 47$ \\
\hline VM.CS & 7.7 & 320.5 & $0.50 \pm 0.05$ & - & $469 \pm 40$ \\
\hline VM.CSM & 7.7 & 320.5 & $0.56 \pm 0.02$ & - & $507 \pm 29$ \\
\hline
\end{tabular}

a Yields of biomass $(\mathrm{X})$ on glucose $(\mathrm{S})$. Biomass yields on glucose higher than 0.5 are due to an underestimation of substrate because in the first phase of the feeding phase biomass is formed from glucose and ethanol.

${ }^{\mathrm{b}}$ At the end of the fermentation. 

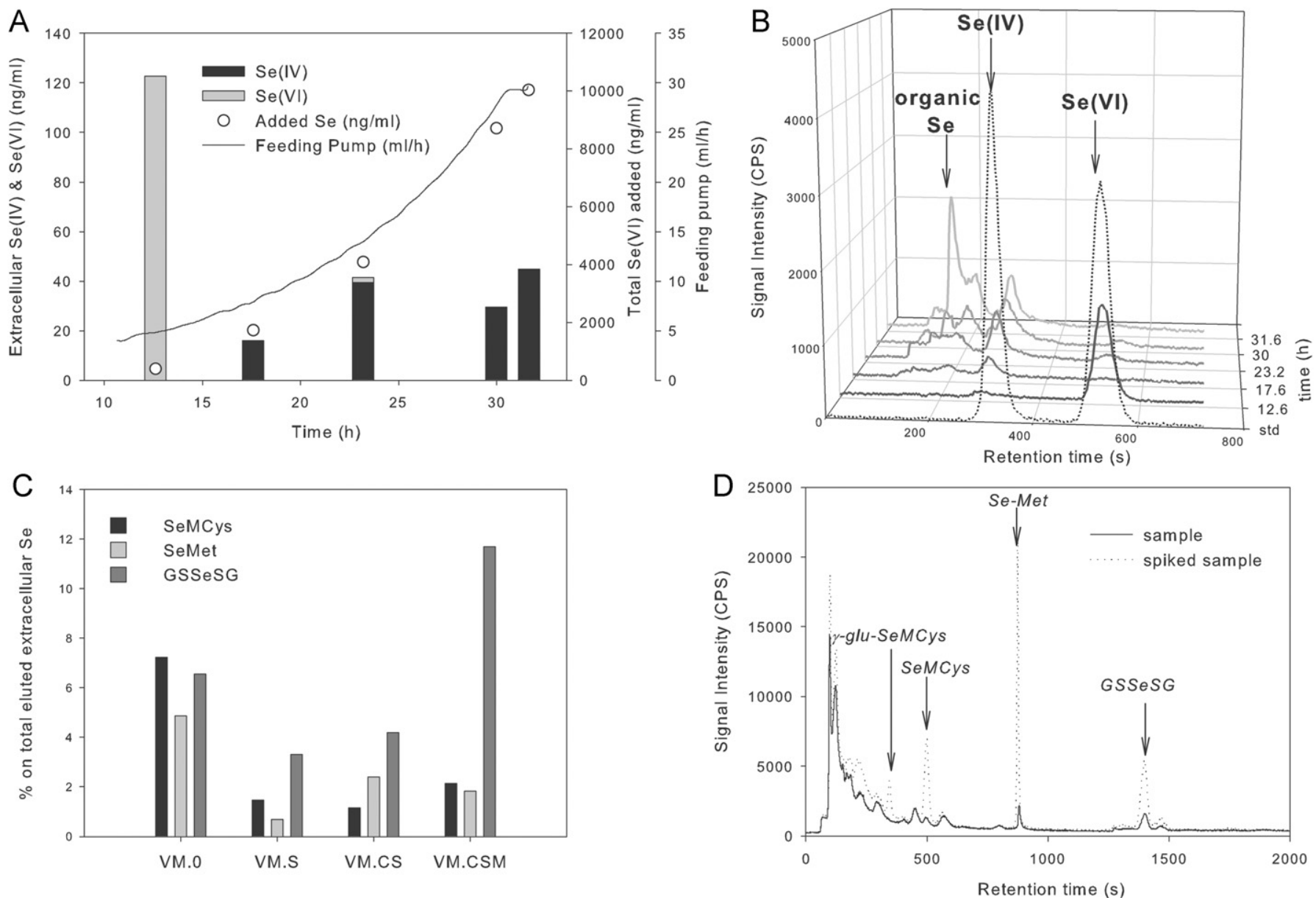

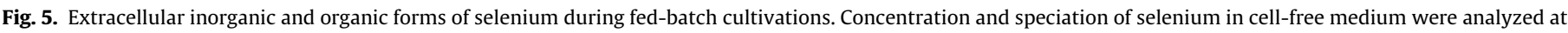

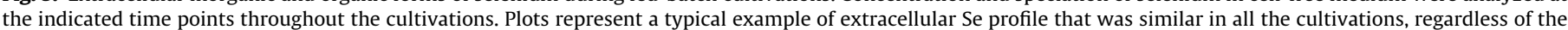

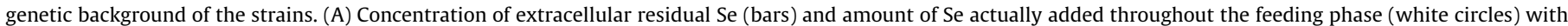

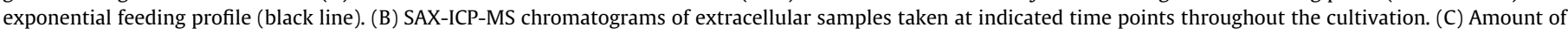

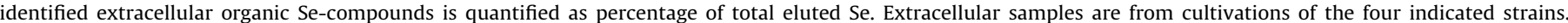

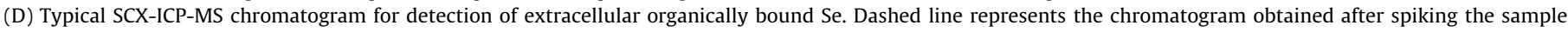
with the four compounds indicated by the arrows.

residual Se was in fact in the more reduced $\mathrm{Se}(\mathrm{IV})$ form (i.e. $\mathrm{SeO}_{3}^{2-}$ ) (Fig. $5 \mathrm{~A}$ and $\mathrm{B}$ ). These observations suggested that the uptake of Se from the medium was complete and that $\mathrm{SeO}_{4}^{2-}$ went through reduction to $\mathrm{SeO}_{3}^{2-}$ (Fig. 1B). Furthermore, the finding of a third early eluting chromatographic peak in the SAX-ICP-MS output (Fig. 5B), possibly corresponding to organic forms of Se, suggested that $\mathrm{SeO}_{4}^{2-}$ went through even further metabolic steps. The presence of organic Se forms was confirmed by SCX-ICP-MS analysis (Fig. 5D) and it was then possible to observe that SeMCys, SeMet, and GSSeSG were actually present in the fermentation broth in the range of $1-12 \%$ out of the total eluted Se (i.e. in the $\mu \mathrm{g} / \mathrm{l}$ range) (Fig. $5 \mathrm{C}$ ). These results represented a first indication that $\mathrm{SeO}_{4}^{2-}$ went through several metabolic steps after its uptake and also that part of the metabolites were thereafter excreted to some extent.

\subsection{VM.CS strain is the best performer in SeMCys biosynthesis}

As shown in Table 4, the concentration of total Se in the biomass harvested at the end of the cultivations reached $450 \mu \mathrm{g} / \mathrm{g}$ DCM. Therefore, accounting for the total amount of Se added to the cultivation, most of it was found in the harvested cells, and the extracellular fraction of Se represented only a very small part of the Se fed throughout the bioprocess. The different genetic backgrounds of the strains did not affect the accumulation of Se; however, the comparison with the certified reference material of selenized yeast SELM-1 (Mester et al., 2006) showed that the amount of total Se in our yeasts was $\sim 4.5$-fold lower (Table 5). Speciation analysis of non-protein-bound Se-metabolites in yeast dry biomass showed that relevant differences between our yeast strains and the reference strains could also be found in terms of organic Se-species (Table 5 and Fig. 6). As expected, SeMet represented the biggest fraction of the Se-metabolite profile in all analyzed yeast strains. Under the established cultivation conditions, a small amount of SeMCys could be detected in the control strain VM.0, but the best performing strain in terms of SeMCys content was VM.CS, co-expressing CHIMERA-1 and optSMT, with a $\sim 24$-fold increase compared to SELM-1 and $\sim 8$-fold increase compared to VM.0 (Table 5). Surprisingly, the amount of SeMCys in VM.CMS strain was lower compared to VM.CS, anyway showing a $\sim 14$ - and 4.7-fold increase compared to SELM-1 and VM.0, respectively.

Since no significant difference in SeMCys levels was found in VM.S compared to VM.0, we could determine that high levels of intracellular SAM, peculiar of strains expressing CHIMERA-1, were essential to achieve substantial increase in SeMCys biosynthesis, likely triggering the selenocysteine methyltransferase reaction 
Table 5

Organic Se-metabolites in cell dry biomass.

\begin{tabular}{|c|c|c|c|c|c|c|c|c|c|}
\hline Strain & $\begin{array}{l}\gamma \text {-glu-SeMCys } \\
\mu \mathrm{g} / \mathrm{g} \text { DCM }\end{array}$ & $\begin{array}{l}\text { FC }^{\mathbf{a}} \gamma \text {-glu- } \\
\text { SeMCys }\end{array}$ & $\begin{array}{l}\text { SeMCys } \\
\mu \mathrm{g} / \mathrm{g} \text { DCM }\end{array}$ & FC SeMCys & $\begin{array}{l}\text { SeMet } \\
\mu \mathrm{g} / \mathrm{g} \text { DCM }\end{array}$ & FC SeMet & $\begin{array}{l}\text { GSSeSG } \\
\mu \mathrm{g} / \mathrm{g} \text { DCM }\end{array}$ & FC GSSeSG & $\begin{array}{l}\text { Total Se } \\
\mu g S e / g \text { DCM }\end{array}$ \\
\hline VM.0 & 0.171 & - & 0.147 & - & 10.155 & - & 0.512 & - & $458 \pm 57$ \\
\hline VM.S & 0.101 & $\downarrow 0.6$ & 0.160 & $\downarrow 1.1$ & 10.026 & $\downarrow 0.9$ & N.D. & & $397 \pm 47$ \\
\hline VM.CS & 0.160 & $\downarrow 0.9$ & 1.140 & $\uparrow 7.7$ & 16.547 & $\uparrow 1.6$ & 1.238 & $\uparrow 2.4$ & $469 \pm 40$ \\
\hline VM.CSM & 0.247 & $\uparrow 1.4$ & 0.691 & $\uparrow 4.7$ & 29.505 & $\uparrow 2.9$ & 0.659 & $\uparrow 1.3$ & $507 \pm 29$ \\
\hline SELM- $1^{\mathrm{b}}$ & 0.064 & & 0.048 & & 0.180 & & B.LOD & & $2096 \pm 75$ \\
\hline Se-PRECISE ${ }^{\mathrm{b}}$ & 0.251 & & B. LOD & & 0.439 & & 0.225 & & $1300^{c}$ \\
\hline
\end{tabular}

N.D.: not detected; B.LOD: below limit of detection.

${ }^{a}$ FC: fold change, VM.0 values are considered as reference values.

${ }^{\mathrm{b}}$ Reference Se-enriched yeasts were analyzed in parallel and with the same technique as all other samples.

c Value from Larsen et al. (2004).

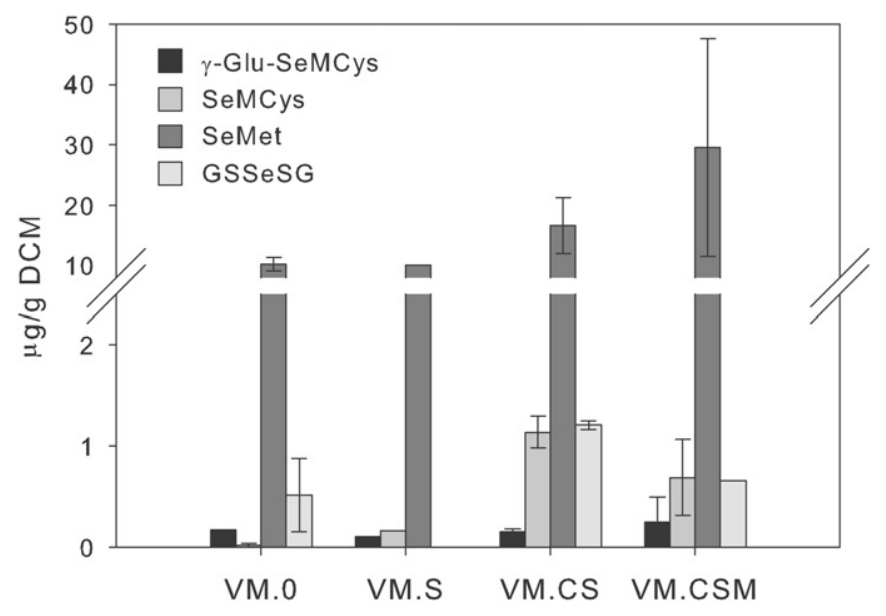

Fig. 6. Selenium speciation in cell dried biomass. Quantification $(\mu \mathrm{g} / \mathrm{g} D C M)$ of the four identified organic Se-compounds in cell biomass of the different recombinant strains. Samples were analyzed via SCX-ICP-MS at the end of the bioprocess.

further. In addition, among the studied yeast strains, VM.CS accumulated the highest levels of $\gamma$-glu-SeMCys and GSSeSG (Fig. 6), possibly increasing the beneficial effects of Se-enriched yeast, if used as Se-supplement.

\subsection{Intracellular $S$ metabolites}

As $\mathrm{S}$ and Se share the same metabolic pathways (Birringer et al., 2002), the co-presence of $S$ and Se sources throughout the cultivations and the introduced genetic modifications might actually affect the balance of the natural and essential metabolism of sulfur compounds in the recombinant strains. Through SCX-ESI-MS/MS analysis, levels of glutathione disulfide (GSSG), reduced glutathione (GSH), methionine (Met), methyl-methionine (MeMet), and methyl-cysteine (MeCys) were monitored throughout the feeding phase of the fed-batch cultivations. No significant levels of MeCys were detected, irrespective of strain genotype (data not shown). This might be due to both the facts that the levels of cysteine in yeast are typically very low and that the specificity of Smt for Cys is lower, compared to SeCys (Neuhierl and Bock, 1996). MeMet was present at quite low levels in all the tested strains (i.e. $<0.3 \mathrm{ng} / \mathrm{g} \mathrm{l}^{-1} \mathrm{DCM}$ ), and even though the expression of optMMT did not result in significant increase in MeMet, it could be noticed that the highest levels of MeMet were detected in strains expressing CHIMERA-1, which was likely favoring the methylation reactions.
The presence of Se sources during yeast growth has been shown to generate a stressful environment for the cells possibly linked to redox imbalance due to an imbalance between GSH and GSSG (Lewinska and Bartosz, 2008; Tarze et al., 2007). Interestingly, the analysis of intracellular GSH and GSSG in our strains throughout the cultivation showed that as long as the concentration of total intracellular Se increased, the ratio GSH:GSSG decreased, due to the increase in GSSG levels (Fig. 7A), regardless of the strain genetic backgrounds. The increase in intracellular GSSG might be the result of spontaneous intracellular reactions between Se-species and reducing thiols (Tarze et al., 2007). Specifically, the reaction between selenite $\left(\mathrm{SeO}_{3}^{2-}\right)$ and $\mathrm{GSH}$ present in excess leads to the formation of GSSG and GSSeSG (reaction 1) and can trigger a series of reactions contributing to the increase in GSSG levels (Tarze et al., 2007) (Fig. 1A).

Reaction 1: $\mathrm{SeO}_{3}^{2-}+4 \mathrm{GSH}+2 \mathrm{H}^{+} \rightarrow \mathrm{GSSeSG}+\mathrm{GSSG}+3 \mathrm{H}_{2} \mathrm{O}$

Although GSSG formation should result in GSH decrease, the latter was not observed, possibly due the fact that GSH was continuously synthesized, therefore resulting in a non-sensible variation. However, these hypotheses need to be further investigated.

Comparing the glutathione profile between the cultivations run with Glc:SO $\mathrm{SO}_{4}^{2-}$ ratio equal to 483 and $320 \mathrm{~g} / \mathrm{g}$, respectively, lower levels of GSSG and GSH were found at lower concentration of $\mathrm{SO}_{4}^{2-}$, whereas the GSH:GSSG ratio was higher under such condition (Fig. 7B). The general lower levels of GSH and GSSG were possibly related to the lower levels of $S$, compared to the condition in which higher levels of $\mathrm{SO}_{4}^{2-}$ were supplied. The higher GSH:GSSG ratio might be due to the lack of GSH excess, which is actually necessary to trigger reaction 1 . Even though these hypotheses are at this point only speculations, the higher levels of GSSeSG found in the presence of higher $\mathrm{SO}_{4}^{2-}$ concentration could be linked to the occurrence of reaction 1 to greater extent, following the excess of GSH (Fig. 7B).

\subsection{Se-metabolite profile is affected by specific bioprocess phase}

In addition to analyzing organic Se-species in yeast biomass, we also extracted intracellular metabolites, aiming to detect a higher number of Se-metabolites. Intracellular metabolites were extracted using the pure methanol method and after quenching of cell metabolism, as reported in Villas-Boas et al. (2005). Metabolites were extracted at different time points throughout the cultivations and analyzed for Se-metabolites with SCX-ICP-MS with the aim of identifying possible differences in metabolic profiles that could be traced back to different physiological states 
A

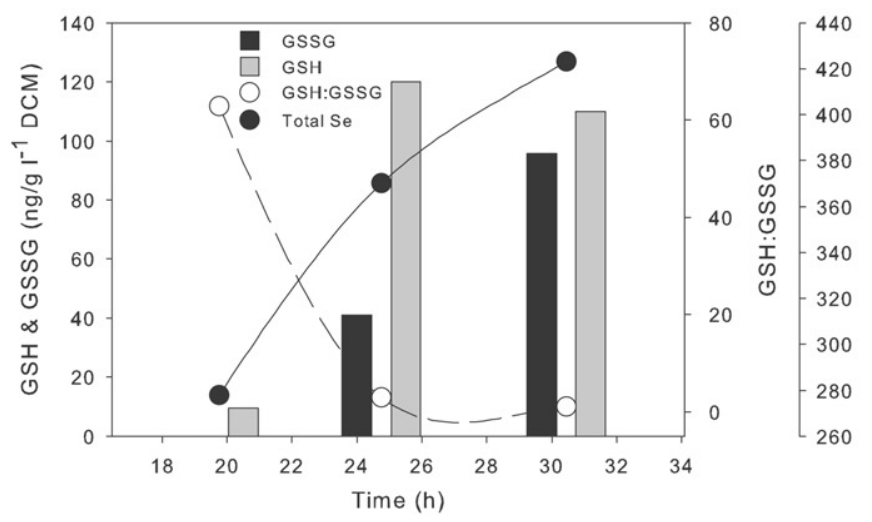

B

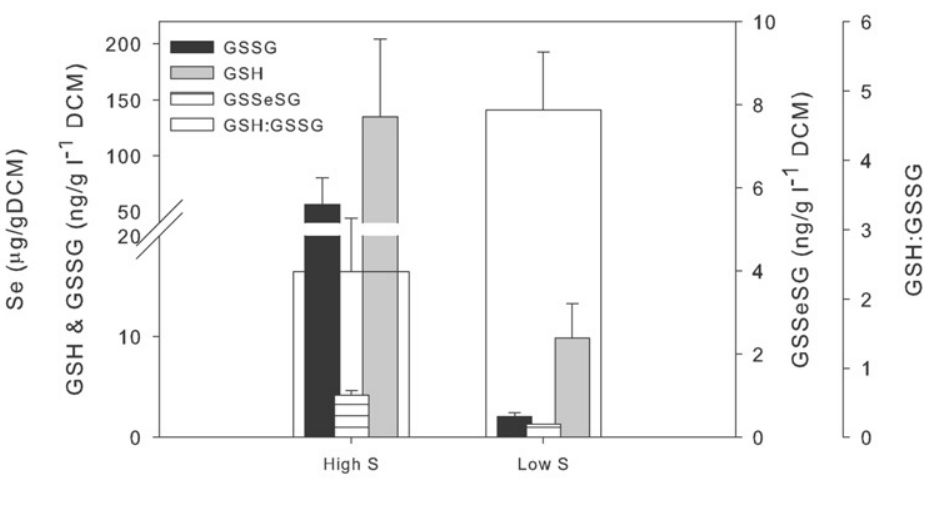

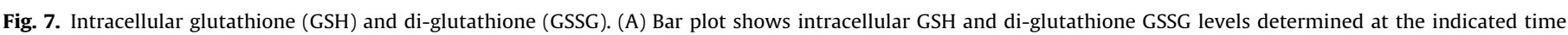

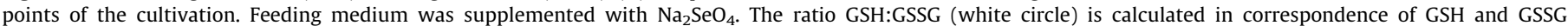

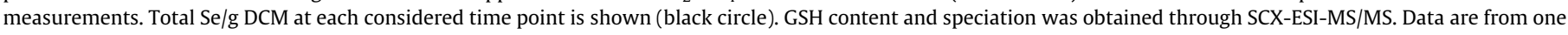

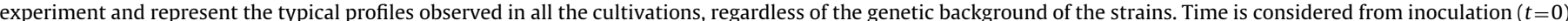

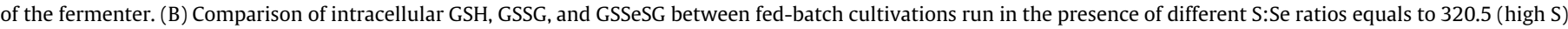
and 483.5 (low S), respectively. GSH:GSSG is calculated from the determined GSH and GSSG levels. Results shown are mean values from 4 individual cultivations.

throughout the bioprocess (Chrysanthopoulos et al., 2010). Principal component analysis (PCA) was used to highlight possible differences among the Se-metabolite fingerprints (i.e. intracellular metabolite profiles) of VM.0, VM.S, VM.CS, and VM.CSM strains: only Se-organic forms were considered. Fig. 8A shows that most of the variation in the Se-metabolite fingerprints is captured by PC1, which explains $22 \%$ of the variation. Interestingly, the two clusters forming along PC1 were not distinguished by different genetic backgrounds of the strains, but by different phases of the bioprocess. In particular, early and late time points (where "late" means at $17-20 \mathrm{~h}$ since the fed batch started or $1 \mathrm{~h}$ after the feed stopped and DCM was $\geq 20 \mathrm{~g} / \mathrm{l}$ ) of the fed-batch phase could be distinguished into two clusters. Unfortunately, most of the Se-metabolites detected could not be identified via our analytical methods; therefore, we could not precisely pinpoint specific metabolites responsible for defining the differences between the two clusters. However, from the loading plot of PC1 versus PC2 (Fig. 8B) we could observe that GSSeSG was highly influencing the separation of the two clusters, as it was significantly higher in the late phase of the cultivations.

\section{Discussion}

SeMCys and $\gamma$-glu-SeMCys are $\mathrm{CH}_{3} \mathrm{SeH}$ precursors in mammal metabolism and are typically present in Se-accumulator edible plants (Birringer et al., 2002). Although Se-accumulator plants are the main natural source of these compounds in the human diet, Se-enriched yeast is the most popular Se-supplement. SeMet is the major Se-metabolite in Se-enriched yeast and it seems to exert beneficial effects to a lower extent than SeMCys and $\gamma$-gluSeMCys (Dong et al., 2001; Ip et al., 2000b; Lippman et al., 2009; Medina et al., 2001). The production of Se-enriched yeast endowed with the ability to synthesize beneficial methylated Se-compounds-SeMCys in particular-was the aim of this work.

Fundamental aspects of yeast physiology in the presence of Se sources were taken into consideration. We show that the efficiency of selenate $\left(\mathrm{SeO}_{4}^{2-}\right)$ uptake by yeast is strictly dependent on the levels of the sulfate $\left(\mathrm{SO}_{4}^{2-}\right)$ source. Regarding the balance of glutathione species, the increase in GSSG levels along with the increase in intracellular Se suggests that the reactions described in Fig. 1A are likely to occur. In particular, as we demonstrate the formation of SeMCys, the presence of SeCys is implied. Hereby, the reaction of SeCys with water (Fig. 1) produces $\mathrm{H}_{2} \mathrm{Se}$ that promptly reacts with two molecules of GSH in the presence of oxygen forming GSSG, which can be formed via further reactions (Tarze et al., 2007) and we hypothesize that excess of GSSG might trigger the formation of $\mathrm{SeO}_{3}^{2-}$ in an excess, subsequently excreted, by favoring the reversal reaction of reaction 1 . The latter hypothesis has to be demonstrated; in fact such reaction does not occur in vitro, but might happen in yeast, due to particular intracellular redox environment (Charlotte Gabel-Jensen, personal communication). GSSG increase leads to a disproportionate GSH:GSSG ratio, compared to the physiological one, thus generating an intracellular redox imbalance (Tarze et al., 2007), which is further boosting under conditions favoring Se uptake (i.e. S-shortage).

Higher levels of intracellular SeMCys were obtained after the expression of OptSMT, the codon optimized smtA gene from A. bisulcatus (Neuhierl and Bock, 1996; Neuhierl et al., 1999). Nonetheless, the introduction of such heterologous enzymatic activity alone is not sufficient to get a significant increase in SeMCys biosynthesis in yeast, while higher levels of SAM obtained with the expression of CHIMERA-1 (Roje et al., 2002) are essential to improve the biosynthesis of SeMCys accounting for a 7.7- and 4.7-fold increase in VM.CS and VM.CSM, respectively. Although the expression of $M M T$ aimed to improve the efficiency of Smt (Neuhierl et al., 1999), which has been shown to have higher affinity for methyl-methionine (MeMet) than for SAM, we surprisingly observe that VM.CS is the best performing strain in terms of SeMCys levels. This phenomenon can be explained by the fact that MeMet is a direct precursor of the highly volatile dimethyl-selenide (DMSe) (Tagmount et al., 2002): the determinant role of $\mathrm{Mmt}$ in facilitating Se volatilization has been demonstrated in A. thaliana and in recombinant $E$. coli expressing a heterologous MMT. Therefore, if such process also occurs in yeast, it will result in an inexorable depletion of selenium source and methyl donor for SeMCys biosynthesis. In order to prove this hypothesis, it would be worth analyzing the volatile Se forms generated throughout yeast fermentations and verifying the presence of MeMet hydrolase activity, which is responsible for DMSe formation in A. thaliana.

This work also shows that bioprocess design is extremely important to tune Se metabolism in yeast. Se metabolism is 
A

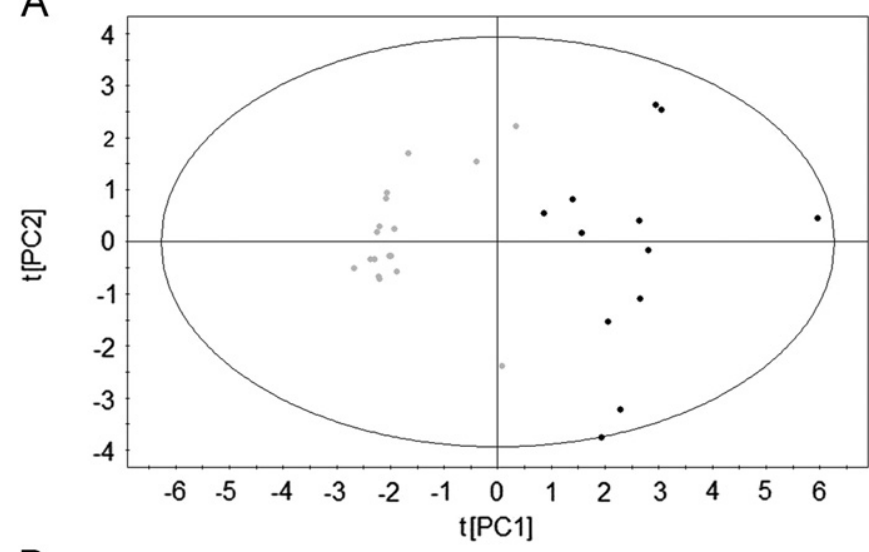

B

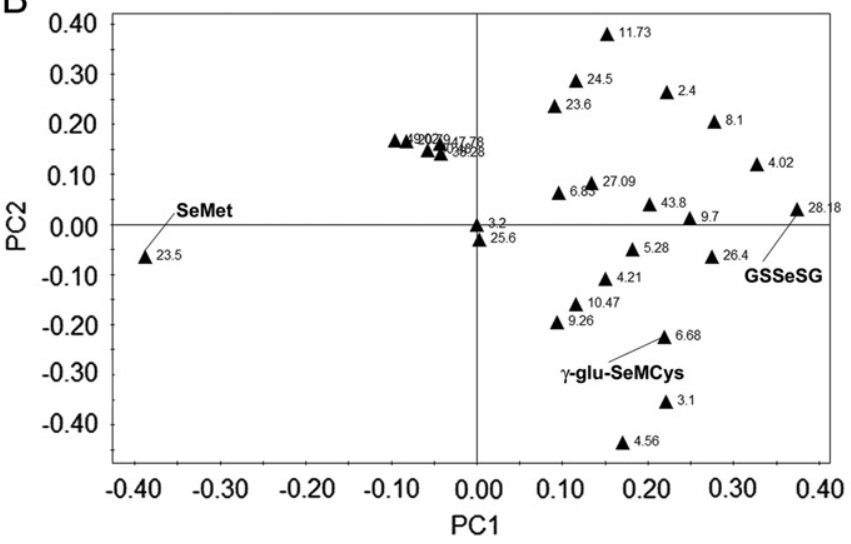

Fig. 8. Principal component analysis of intracellular Se-metabolite profiles at different time points during fed-batch cultivations. PCA was performed according to Hotelling T-square statistics using SIMCA-P v. 10.5.0.0 (Umetrics $A B$, Umeå, Sweden). (A) Score plot. Each dot represents a single Se-metabolite profile from VM.0, VM.CS, and VM.CSM. Gray dots correspond to early time points during the fed-batch phase, black dots represent late time points during the fed-batch phase. Colors have been assigned to better visualize the two different clusters. (B) Loading plot. Each metabolite is identified by the specific retention time. The plot shows the contribution of each Se-metabolite in determining the position of the metabolite profiles in the score plot.

greatly affected by the different phases of the bioprocess (Fig. 8) that can be discriminated through analysis of metabolic profiles. Such data assess the high potentiality of metabolomics for the development and monitoring of laboratory and industrial bioprocesses (Chrysanthopoulos et al., 2010). The choice of a fed-batch process is linked to the need to achieve high biomass levels, according to an industrial production perspective, and to the possibility that such process gives in terms of growth and feed modulation. The range of Glc: $\mathrm{SO}_{4}^{2-}$ ratio within which we can play while keeping the two components at limiting concentration is quite broad (Table 3), while the $\mathrm{SO}_{4}^{2-}: \mathrm{SeO}_{4}^{2-}$ ratio is much more critical when operating under $\mathrm{SO}_{4}^{2-}$ limiting conditions. In fact, at $\mathrm{SO}_{4}^{2-}: \mathrm{SeO}_{4}^{2-}$ ratio equal to $5.1: 1(\mathrm{~g} / \mathrm{g})$ the toxicity of Se is much more evident, compared to a $\mathrm{SO}_{4}^{2-}: \mathrm{SeO}_{4}^{2-}$ ratio equal to $7.7: 1$ $(\mathrm{g} / \mathrm{g})$, such that cells cannot sustain the settled $\mu=0.1 \mathrm{~h}^{-1}$ and undergo fermentation due to carbon overflow through the glycolytic pathway (Table 4). Further optimization of the established bioprocess might be performed by testing the effect of $\mathrm{Glc}_{\mathrm{SO}}{ }_{4}^{2-}$ ratios lower than 320.5. Increasing $\mathrm{SO}_{4}^{2-}$ levels within the limiting range might further diminish the toxicity of Se by possibly buffering the redox imbalance due to the affected GSH:GSSG ratio.

The comparison of our recombinant strains with SELM-1 Seenriched yeast (Mester et al., 2006) shows that we achieved a $\sim 24$-fold increase in SeMCys. The differences in non-proteinbound Se-metabolites and in Se/g DCM between our control strain VM.0 and the two selenized yeast references (Table 4) highlight the drastic influence of genetic background and bioprocess parameter on yeast Se-metabolite profile. The low content of SeMet obtained for SELM-1 and Se-PRECISE in this work (Table 5), compared to the previously reported values (Larsen et al., 2004; Mester et al., 2006), can be linked to different treatments of yeast biomass prior to the analysis. Here we only take into consideration the non-protein-bound Se-species, while in Larsen et al. (2004) and Mester et al. (2006) yeast has been subjected to digestion treatments that liberate protein-bound Se-species and SeMet in particular. Avoiding the presence of inorganic Se forms is carefully considered during the production of selenized yeast, as it can cause accumulation of $\mathrm{H}_{2} \mathrm{Se}$ (Fig. 1C), which is associated with a variety of genotoxic effects (Ip et al., 2000b). Our bioprocess results in Se-enriched yeast containing from 7\% to a maximum of $10 \%$ inorganic Se out of the total eluted Se, which is comparable with the content of inorganic Se found in commercial selenized yeast. In spite of increased levels of SeMCys, SeMet remains the main Se-organic species in our yeast, ranging from ca. 10 to $30 \mu \mathrm{g} / \mathrm{g}$ DCM. Although altering the biosynthesis of SeMet represents a big challenge, as it cannot be modified without affecting the essential metabolism of methionine, successful strategies to limit the accumulation of SeMet and its non-specific incorporation into proteins would further increase the beneficial potential of Se-enriched yeast. Furthermore, a better understanding of the molecular mechanisms triggering the excretion of organic Se-compounds would be desirable with the aim of maximizing their intracellular accumulation.

In conclusion, we report here a metabolic engineering strategy that leads to significant improvement of the Se-metabolite profile of Se-enriched yeast on the basis of the health-promoting effects of methylated Se-compounds, such as SeMCys. The combination of CHIMERA-1 and OptSMT heterologous expression was determinant in order to achieve the biosynthesis of the target compound. We also show that a fine tuned bioprocess, in particular a dual $\mathrm{C}$ - and S-limitation, is necessary to maximize the desired metabolic features and to minimize the toxic effects due to the presence of Se. Furthermore, the controlled conditions realized in the fed-batch cultivations helped in defining critical nodes in the interplay between sulfur and selenium metabolism. Therefore, we can now hypothesize that a redox imbalance due to the affected intracellular GSH:GSSG ratio is at least one of the factors connected to Se toxicity on yeast. A number of considerations regarding the fundamental physiology of yeast in the presence of Se are brought into light and such knowledge will help to further optimize both the metabolic engineering strategies and the bioprocess. Whether the beneficial properties of the obtained Se-enriched yeast have been improved, compared to the existing yeast-based Se supplements, has to be carefully tested. With this aim, an animal study using our selenized recombinant yeast is now ongoing.

\section{Acknowledgments}

The authors would like to thank Dr. Andrew D. Hanson (University of Florida, USA) for kindly providing the plasmid CHIMERA1-pVT103-U, Dr. Li Li (Cornell University, USA) for kindly providing the plasmid pTriplEx_BoSMT, Christian Thörn for technical help throughout the ongoing study, and all the partners of the YESSEL project for very fruitful discussions. This research was financed by the Danish Research Agency via the YESSEL project "Biosynthesis of cancer preventive organoselenium compounds by metabolically engineered yeast". 


\section{References}

Birringer, M., Pilawa, S., Flohe, L., 2002. Trends in selenium biochemistry. Nat. Prod. Rep. 19, 693-718.

Block, E., 1996. Recent results in the organosulfur and organoselenium chemistry of genus Allium and Brassica plants. Relevance for cancer prevention. Adv. Exp. Med. Biol. 401, 155-169.

Boer, V.M., de Winde, J.H., Pronk, J.T., Piper, M.D., 2003. The genome-wide transcriptional responses of Saccharomyces cerevisiae grown on glucose in aerobic chemostat cultures limited for carbon, nitrogen, phosphorus, or sulfur. J. Biol. Chem. 278, 3265-3274.

Cai, X.J., Block, E., Uden, P.C., Zhang, X., Q., B.D., Sullivan, J.J., 1995. Allium chemistry: identification of selenoamino acids in ordinary and seleniumenriched garlic, onion, and broccoli using gas-chromatography with atomicemission detection. J. Agric. Food Chem. 43, 1754-1757.

Chrysanthopoulos, P.K., Goudar, C.T., Klapa, M.I., 2010. Metabolomics for highresolution monitoring of the cellular physiological state in cell culture engineering. Metab. Eng. 12, 212-222.

Clark, L.C., Combs Jr., G.F., Turnbull, B.W., Slate, E.H., Chalker, D.K., Chow, J., Davis L.S., Glover, R.A., Graham, G.F., Gross, E.G., Krongrad, A., Lesher Jr., J.L., Park, H.K., Sanders Jr., B.B., Smith, C.L., Taylor, J.R., 1996. Effects of selenium supplementation for cancer prevention in patients with carcinoma of the skin. A randomized controlled trial. Nutritional Prevention of Cancer Study Group. J. Am. Med. Assoc. 276, 1957-1963.

Demirci, A., Pometto III, A.L., 1999. Production of organically bound selenium yeast by continuous fermentation. J. Agric. Food Chem. 47, 2491-2495.

Demirci, A., Pometto III, A.L., Cox, D.J., 1999. Enhanced organically bound selenium yeast production by fed-batch fermentation. J. Agric. Food Chem. 47, 2496-2500.

Dernovics, M., Far, J., Lobinski, R., 2009. Identification of anionic selenium species in Se-rich yeast by electrospray QTOF MS/MS and hybrid linear ion trap/ orbitrap MS. Metallomics 1, 317-329.

Dong, Y., Lisk, D., Block, E., Ip, C., 2001. Characterization of the biological activity of gamma-glutamyl-Se-methylselenocysteine: a novel, naturally occurring anticancer agent from garlic. Cancer Res. 61, 2923-2928.

Egli, T., Zinn, M., 2003. The concept of multiple-nutrient-limited growth of microorganisms and its application in biotechnological processes. Biotechnol Adv. 22, 35-43.

Far, J., Preud'homme, H., Lobinski, R., 2010. Detection and identification of hydrophilic selenium compounds in selenium-rich yeast by size exclusionmicrobore normal-phase HPLC with the on-line ICP-MS and electrospray Q-TOF-MS detection. Anal. Chim. Acta 657, 175-190.

Gietz, R.D., Sugino, A., 1988. New yeast-Escherichia coli shuttle vectors constructed with in vitro mutagenized yeast genes lacking six-base pair restriction sites. Gene 74, 527-534

Gietz, R.D., Woods, R.A., 2002. Transformation of yeast by lithium acetate/singlestranded carrier DNA/polyethylene glycol method. Methods Enzymol. 350, 87-96.

Grote, A., Hiller, K., Scheer, M., Munch, R., Nortemann, B., Hempel, D.C., Jahn, D. 2005. JCat: a novel tool to adapt codon usage of a target gene to its potential expression host. Nucl. Acids Res. 33, W526-W531.

Hahn-Hägerdal, B., Karhumaa, K., Larsson, C.U., Gorwa-Grauslund, M., Gorgens, J. van Zyl, W.H., 2005. Role of cultivation media in the development of yeast strains for large scale industrial use. Microb. Cell Fact. 4, 31

Ip, C., Birringer, M., Block, E., Kotrebai, M., Tyson, J.F., Uden, P.C., Lisk, D.J., 2000a. Chemical speciation influences comparative activity of selenium-enriched garlic and yeast in mammary cancer prevention. J. Agric. Food Chem. 48, 4452

Ip, C., Hayes, C., Budnick, R.M., Ganther, H.E., 1991. Chemical form of selenium, critical metabolites, and cancer prevention. Cancer Res. 51, 595-600.

Ip, C., Thompson, H.J., Zhu, Z., Ganther, H.E., 2000b. In vitro and in vivo studies of methylseleninic acid: evidence that a monomethylated selenium metabolite is critical for cancer chemoprevention. Cancer Res. 60, 2882-2886.

Kápolna, E., Hillestrøm, P.R., Laursen, K.H., Husted, S., Larsen, E.H., 2009. Effect of foliar application of selenium on its uptake and speciation in carrot. Food Chem. 115, 1357-1363.

Kotrebai, M., Birringer, M., Tyson, J.F., Block, E., Uden, P.C., 2000. Selenium speciation in enriched and natural samples by HPLC-ICP-MS and HPLC-ESIMS with perfluorinated carboxylic acid ion-pairing agents. Analyst 125, 71-78.

Larsen, E.H., Hansen, M., Paulin, H., Moesgaard, S., Reid, M., Rayman, M., 2004. Speciation and bioavailability of selenium in yeast-based intervention agents used in cancer chemoprevention studies. J. Aoac Int. 87, 225-232.

Lee, S.O., Yeon Chun, J., Nadiminty, N., Trump, D.L., Ip, C., Dong, Y., Gao, A.C., 2006 Monomethylated selenium inhibits growth of LNCaP human prostate cancer xenograft accompanied by a decrease in the expression of androgen receptor and prostate-specific antigen (PSA). Prostate 66, 1070-1075.

Lewinska, A., Bartosz, G., 2008. A role for yeast glutaredoxin genes in selenitemediated oxidative stress. Fungal Genet. Biol. 45, 1182-1187.

Lippman, S.M., Klein, E.A., Goodman, P.J., Lucia, M.S., Thompson, I.M., Ford, L.G. Parnes, H.L., Minasian, L.M., Gaziano, J.M., Hartline, J.A., Parsons, J.K., Bearden 3rd, J.D., Crawford, E.D., Goodman, G.E., Claudio, J., Winquist, E., Cook, E.D., Karp, D.D., Walther, P., Lieber, M.M., Kristal, A.R., Darke, A.K., Arnold, K.B., Ganz, P.A., Santella, R.M., Albanes, D., Taylor, P.R., Probstfield, J.L., Jagpal, T.J., Crowley, J.J., Meyskens Jr., F.L., Baker, L.H., Coltman Jr., C.A., 2009. Effect of selenium and vitamin $\mathrm{E}$ on risk of prostate cancer and other cancers: the Selenium and Vitamin E Cancer Prevention Trial (SELECT). J. Am. Med. Assoc. 301, 39-51.

Lu, P., Rangan, A., Chan, S.Y., Appling, D.R., Hoffman, D.W., Marcotte, E.M., 2007. Global metabolic changes following loss of a feedback loop reveal dynamic steady states of the yeast metabolome. Metab. Eng. 9, 8-20.

Lyi, S.M., Heller, L.I., Rutzke, M., Welch, R.M., Kochian, L.V., Li, L., 2005. Molecular and biochemical characterization of the selenocysteine Se-methyltransferase gene and Se-methylselenocysteine synthesis in broccoli. Plant Physiol. 138, 409-420.

Medina, D., Thompson, H., Ganther, H., Ip, C., 2001. Se-methylselenocysteine: a new compound for chemoprevention of breast cancer. Nutr. Cancer. 40, 12-17.

Mester, Z., Willie, S., Yang, L., Sturgeon, R., Caruso, J.A., Fernandez, M.L., Fodor, P., Goldschmidt, R.J., Goenaga-Infante, H., Lobinski, R., Maxwell, P., McSheehy, S. Polatajko, A., Sadi, B.B., Sanz-Medel, A., Scriver, C., Szpunar, J., Wahlen, R., Wolf, W., 2006. Certification of a new selenized yeast reference material (SELM-1) for methionine, selenomethinone and total selenium content and its use in an intercomparison exercise for quantifying these analytes. Anal. Bioanal. Chem. $385,168-180$

Mumberg, D., Muller, R., Funk, M., 1995. Yeast vectors for the controlled expression of heterologous proteins in different genetic backgrounds. Gene 156, 119-122.

Neuhierl, B., Bock, A., 1996. On the mechanism of selenium tolerance in seleniumaccumulating plants. Purification and characterization of a specific selenocysteine methyltransferase from cultured cells of Astragalus bisculatus. Eur. J. Biochem. 239, 235-238.

Neuhierl, B., Thanbichler, M., Lottspeich, F., Bock, A., 1999. A family of S-methylmethionine-dependent thiol/selenol methyltransferases. Role in selenium tolerance and evolutionary relation. J. Biol. Chem. 274, 5407-5414.

Nielsen, J., Villadsen, J., Liden, G., 2002. Bioreaction Engineering Principles, 2nd ed. Kluwer Academic/Plenum Publishers (Now: Springer Verlag), New York.

Rayman, M.P., 2005. Selenium in cancer prevention: a review of the evidence and mechanism of action. Proc. Nutr. Soc. 64, 527-542.

Roje, S., Chan, S.Y., Kaplan, F., Raymond, R.K., Horne, D.W., Appling, D.R., Hanson, A.D., 2002. Metabolic engineering in yeast demonstrates that S-adenosylmethionine controls flux through the methylenetetrahydrofolate reductase reaction in vivo. J. Biol. Chem. 277, 4056-4061.

Sambrook, J., Russel, D.W., 2001. Molecular Cloning: A Laboratory Manual, third ed. Cold Spring Harbor Laboratory Press, Cold Spring Harbor, New York, USA.

Shrift, A., Virupaksha, T.K., 1963. Biosynthesis of Se-methyl-selenocysteine from selenite in selenium-accumulating plants. Biochim. Biophys. Acta 14, 483-485.

Tagmount, A., Berken, A., Terry, N., 2002. An essential role of s-adenosylL-methionine:L-methionine s-methyltransferase in selenium volatilization by plants. Methylation of selenomethionine to selenium-methyl-L-seleniummethionine, the precursor of volatile selenium. Plant Physiol. 130, 847-856.

Tarze, A., Dauplais, M., Grigoras, I., Lazard, M., Ha-Duong, N.T., Barbier, F., Blanquet, S., Plateau, P., 2007. Extracellular production of hydrogen selenide accounts for thiol-assisted toxicity of selenite against Saccharomyces cerevisiae. J. Biol. Chem. 282, 8759-8767.

Treadwell, F.P., 1924. Analytical Chemistry. John Wiley and Son, New York.

Trelease, S.F., DiSomma, A.A., Jacobs, A.L., 1960. Seleno-amino acid found in Astragalus bisulcatus. Science 132, 618

Verduyn, C., Postma, E., Scheffers, W.A., Van Dijken, J.P., 1992. Effect of benzoic acid on metabolic fluxes in yeasts: a continuous-culture study on the regulation of respiration and alcoholic fermentation. Yeast 8, 501-517.

Villas-Boas, S.G., Hojer-Pedersen, J., Akesson, M., Smedsgaard, J., Nielsen, J., 2005. Global metabolite analysis of yeast: evaluation of sample preparation methods. Yeast 22, 1155-1169.

Whanger, P.D., 2004. Selenium and its relationship to cancer: an update. Br. J. Nutr. $91,11-28$

Zha, W., Rubin-Pitel, S.B., Shao, Z., Zhao, H., 2009. Improving cellular malonyl-CoA level in Escherichia coli via metabolic engineering. Metab. Eng. 11, 192-198. 